\title{
Simulation of urban boundary and canopy layer flows in port areas induced by different marine boundary layer inflow conditions
}

Citation for published version (APA):

Ricci, A., Burlando, M., Repetto, M. P., \& Blocken, B. (2019). Simulation of urban boundary and canopy layer flows in port areas induced by different marine boundary layer inflow conditions. Science of the Total

Environment, 670, 876-892. https://doi.org/10.1016/j.scitotenv.2019.03.230

Document license:

TAVERNE

DOI:

10.1016/j.scitotenv.2019.03.230

Document status and date:

Published: 20/06/2019

Document Version:

Publisher's PDF, also known as Version of Record (includes final page, issue and volume numbers)

Please check the document version of this publication:

- A submitted manuscript is the version of the article upon submission and before peer-review. There can be important differences between the submitted version and the official published version of record. People interested in the research are advised to contact the author for the final version of the publication, or visit the $\mathrm{DOI}$ to the publisher's website.

- The final author version and the galley proof are versions of the publication after peer review.

- The final published version features the final layout of the paper including the volume, issue and page numbers.

Link to publication

\footnotetext{
General rights

- You may freely distribute the URL identifying the publication in the public portal. follow below link for the End User Agreement:

www.tue.nl/taverne

Take down policy

If you believe that this document breaches copyright please contact us at:

openaccess@tue.nl

providing details and we will investigate your claim.
}

Copyright and moral rights for the publications made accessible in the public portal are retained by the authors and/or other copyright owners and it is a condition of accessing publications that users recognise and abide by the legal requirements associated with these rights.

- Users may download and print one copy of any publication from the public portal for the purpose of private study or research.

- You may not further distribute the material or use it for any profit-making activity or commercial gain

If the publication is distributed under the terms of Article $25 \mathrm{fa}$ of the Dutch Copyright Act, indicated by the "Taverne" license above, please 


\title{
Simulation of urban boundary and canopy layer flows in port areas induced by different marine boundary layer inflow conditions
}

\author{
A. Ricci ${ }^{\text {a,b,c,* }}$, M. Burlando ${ }^{\text {c }}$, M.P. Repetto ${ }^{\text {c }}$, B. Blocken ${ }^{\text {a,b }}$ \\ a Department of Civil Engineering, KU Leuven, Leuven, Belgium \\ ${ }^{\mathrm{b}}$ Department of the Built Environment, Eindhoven University of Technology, Eindhoven, the Netherlands \\ c Department of Civil, Chemical and Environmental Engineering (DICCA), University of Genoa, Genoa, Italy
}

\section{H I G H L I G H T S}

- Wind-tunnel (WT) tests CFD simulations were performed on a reduced urban model.

- Three different sets of inflow profiles were simulated by 3D steady RANS approach.

- Mean wind speed profiles of WT tests and CFD simulations were compared.

- The use of different inflow wind speed profiles is almost not relevant in the UCL.

- Different inflow wind speed profiles strongly affected the results above the UCL.

\section{A R T I C L E I N F O}

\section{Article history:}

Received 11 January 2019

Received in revised form 28 February 2019

Accepted 15 March 2019

Available online 16 March 2019

Editor: Pavlos Kassomenos

\section{Keywords:}

Urban wind flows

LiDAR measurements

Marine boundary layer, wind-tunnel tests

CFD simulations

Inflow conditions
G R A P H I C A L A B S T R A C T

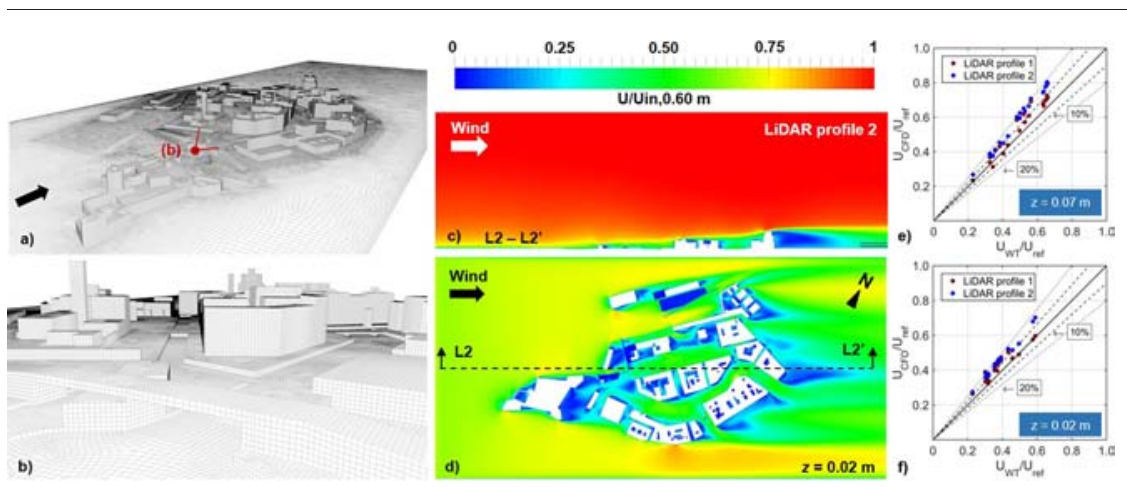

\section{A B S T R A C T}

Computational fluid dynamics (CFD) simulations and wind-tunnel (WT) tests can be considered as boundaryvalue problems, where the inlet boundary condition, which is usually obtained inferring inlet mean wind profiles from on-site measurements or other type of experimental data, represents the large-scale atmospheric forcing exerted at the outer limit of the urban model. It is not clear, however, to which extent the choice of different inflow wind speed profiles may affect WT and CFD results in the urban environment. In the present study, this aspect is investigated through the comparison of the wind flow fields simulated numerically and tested experimentally in an atmospheric boundary layer wind tunnel (ABLWT) within a district of Livorno city, Italy, called "Quartiere La Venezia". Three different shapes of inflow profiles were tested using the CFD technique and the results were compared with each other: one is based on the approach-flow profiles measured upstream of the urban model in the WT test section (WT profile) and two are based on anemometric data corresponding to the approach-flow profile measured by means of a LiDAR wind profiler (LiDAR profile 1 and 2). The analysis showed that using different wind speed profiles does not affect significantly the results in the urban canopy layer (UCL), where correlations of $95 \%$ and $98 \%$ were found between the LiDAR profile 1 and 2 data and the WT profile data (at $z=0.02 \mathrm{~m}$ above the bottom), respectively. Conversely, the different inflow profiles strongly affected the results above the UCL. This means that the local-scale effects induced on the wind field in the UCL by the urban texture are dominated mainly by the larger-scale forcing, as within the canopy the flow remains topologically invariant despite the different inflow conditions.

(C) 2019 Elsevier B.V. All rights reserved.

\footnotetext{
* Corresponding author at: Department of the Built Environment, Eindhoven University of Technology, Eindhoven, the Netherlands.

E-mail addresses: a.ricci@tue.nl, alessio.ricci@kuleuven.be, alessio.ricci@unige.it (A. Ricci), massimiliano.burlando@unige.it (M. Burlando), repetto@dicca.unige.it (M.P. Repetto), bert.blocken@kuleuven.be, b.j.e.blocken@tue.nl (B. Blocken).
} 


\section{Introduction}

The energy driving the wind flow at the urban scale mainly comes from the forcing at larger spatial scales, which ultimately relates to the large-scale meteorological conditions that change continuously in time. From this point of view, both the numerical (e.g. CFD simulations) and experimental (e.g. WT tests) techniques, which are commonly adopted to study wind flows in urban environments, can be seen as boundary-value problems, where the boundary conditions describe the large-scale atmospheric forcing exerted at the outer limits of the urban model (Mochida et al., 2011). In practice, the definition of the proper large-scale meteorological conditions driving the wind flow in urban areas is not a trivial issue because on-site anemometric experimental data are often not available or it consists at most of single stations located on top of buildings or on antenna masts. The inlet profiles, therefore, are commonly extrapolated assuming a priori that a power law or a logarithmic law wind profile valid under neutral atmospheric stability conditions holds above the urban canopy (Kondo et al., 2006; Schatzmann and Leitl, 2011; Tominaga and Stathopoulos, 2013).

However, irrespective of the accuracy of the wind measurements, the mean wind speed and turbulence intensity profiles calculated from single point data using the most common formulations (e.g. the logarithmic law, characterized uniquely by the two parameters friction velocity, $u^{*}$, and aerodynamic roughness length, $z_{0}$, or the power law, characterized by the exponent $\alpha$ ) can show large deviations with respect to the reality, especially if atmospheric stability conditions are not neutral. In fact, a specific location can be characterized by several different neutral as well as non-neutral atmospheric stability conditions, which makes the definition of the proper boundary conditions for the wind flow extremely complicated. Mean wind speeds greater than 6-7 m/s, which are of interest in structural wind engineering, are expected to correspond to neutral conditions in the atmosphere (Pasquill, 1961; Stull, 1988; Venkatram, 1996; Repetto, 2011), whereas pollution dispersion studies usually focus on lower wind speed conditions (Santiago et al., 2013; Tominaga and Stathopoulos, 2013, 2016). This variability may be quantified using instruments able to measure the real time-dependent vertical and horizontal wind velocity profile such as Sonic (SoDAR) or Light Detection And Ranging (LiDAR) wind profilers (IEA, 2013; Fujii and Fukuchi, 2005; Emeis et al., 2007; Solari, 2014).

In order to understand to which extent different inflow wind profiles can influence the flow field in the urban canopy layer (UCL) and more broadly in the urban boundary layer (UBL), the present study focuses on neutral conditions only. This is the easiest and very common approach adopted in WT as well as CFD, and it can be found in several previous publications dealing with the wind flow modeling over random urban-like obstacles (e.g. Xie et al., 2008), uniform and staggered building arrays (e.g. Coceal and Belcher, 2004; Xie and Castro, 2006; An et al., 2013), idealized urban surfaces (e.g. Cheng and Porté-Agel, 2015; Sha et al., 2018), real and idealized isolated buildings (e.g. Montazeri and Blocken, 2013; Iousef et al., 2017; van Hooff et al., 2017; Vasaturo et al., 2018a) semi-idealized, real urban canopies and street canyons (e.g. Buccolieri et al., 2009; Hertwig et al., 2012; Carpentieri and Robins, 2015; Santiago et al., 2017; Zhang et al., 2019), complex and flat terrains and urban areas (e.g. Kastner-Klein and Rotach, 2004; Gromke et al., 2008; Blocken et al., 2012, 2015, 2016; Carpentieri et al., 2012; Janssen et al., 2013; García Sánchez et al., 2014, 2018; Tominaga and Stathopoulos, 2013; Jeanjean et al., 2015; Antoniou et al., 2017; Hornikx et al., 2018; Vasaturo et al., 2018b).

Moreover, without loss of generality (Meroney, 2016), a numerical approach rather than an experimental one was chosen in the present paper to test how different neutral inflow conditions, i.e. mean wind speed and turbulence profiles, can influence the urban flows. One of the main advantages of this approach is that inlet atmospheric boundary conditions are easier to change rather than in boundary layer wind tunnels (BLWT), where the fine tuning of the inflow profiles (both in terms of mean wind speed and turbulence characteristics) may require quite a long time to find out the configuration of passive devices (e.g. spires, fences, and roughness elements) needed to generate a proper neutral atmospheric profile (Lloyd, 1967; Armitt and Counihan, 1968; Counihan, 1969, 1970; Cermak, 1972; Irwin, 1980; Plate, 1982, 1999; Farell and Iyengar, 1999; Balendra et al., 2002; Kozmar, 2010, 2011).

Hence, in the present study, CFD simulations of the wind flows through and over the urban district called "Quartiere La Venezia" in Livorno, Italy, were performed for one reference wind direction corresponding to the wind blowing from the sea during Libeccio events (i.e. WSW). Three different simulations were performed according to the available on-site measurements derived from the monitoring network of the European projects "Wind and Ports" (WP) and "Wind, Ports, and Sea" (WPS) (Solari et al., 2012; Burlando et al., 2014, 2017; Repetto et al., 2017a, 2017b). In particular, as WT tests were also available for this urban district at the reduced-scale 1:300 (Ricci et al., 2017a), the same wind profiles measured approximately $1 \mathrm{~m}$ upstream of the urban model in the WT, termed "WT profile" set hereafter, was chosen for the sake of comparison as well as for the validation of the present computational grid (Ricci et al., 2017b). The second and the third inflow wind profiles, termed "LiDAR profile 1" and "LiDAR profile 2" hereafter, are based on statistical analyses performed on on-site measurements carried out by a LiDAR wind profiler installed very close to the sea and the area under investigation (i.e. Quartiere La Venezia). These wind profiles are assumed to be uniform in the span-wise direction, for a measured reference wind direction (as in the present case for $\alpha=240^{\circ}$ ), at the inlet face of the computational domain. This assumption was investigated by Ricci et al. (2018) where CFD simulations on the same reduced-scale urban model (i.e. Quartiere La Venezia) were performed taking into account span-wise gradients in the ABL profiles measured in the WT upstream of the urban model. The results of Ricci et al. (2018) showed that using profiles with span-wise gradients as well as slightly different formulations to define the inlet turbulent kinetic energy $(k)$ and turbulence dissipation rate $(\varepsilon)$ profiles lead to comparable numerical results within the UCL. This means that at the building scale there is no need to use more accurate boundary conditions because they are as effective as the simpler ones.

The paper is organized as follows. Section 2 contains a description of the area of interest and the monitoring network. In Section 3 the selection of inflow conditions from the LiDAR measurements are described. Section 4 shows a short description of the WT tests performed on the reduced-scale urban district. Section 5 presents the computational settings and parameters adopted to perform the 3D steady RANS simulations for the same reduced-scale urban model. Section 6 presents the CFD results in terms of contours of wind speed ratio and the comparison between WT and CFD results in terms of mean wind speed profiles. In Section 7 the agreement between WT and CFD results is quantified using validation metrics. Finally, Section 8 concludes the paper with discussion and conclusions.

\section{Area of interest and monitoring network}

The urban area chosen as test case in the present study is a historical district of Livorno city, Italy, called "Quartiere La Venezia" (Fig. 1). This area is particularly interesting for the following reasons: (i) it is quite similar to many other historical districts in European cities from the point of view of geometry and morphology so that it may become a benchmark for further investigations of real neighborhoods with similar characteristics; (ii) it was already intensely investigated by on-site measurements (Solari et al., 2012; Burlando et al., 2014, 2017; Repetto et al., 2017a, 2017b), by WT tests (Ricci et al., 2017a), by CFD simulations (Ricci et al., 2017b, 2018) and the validated numerical results of the urban district are now available for further investigations; (iii), the wind flow field in the nearby westward port area is monitored by several anemometers and a wind profiler, which have measured the wind conditions exactly upwind of the district during some dangerous strong sea storms that occurred in Livorno. 

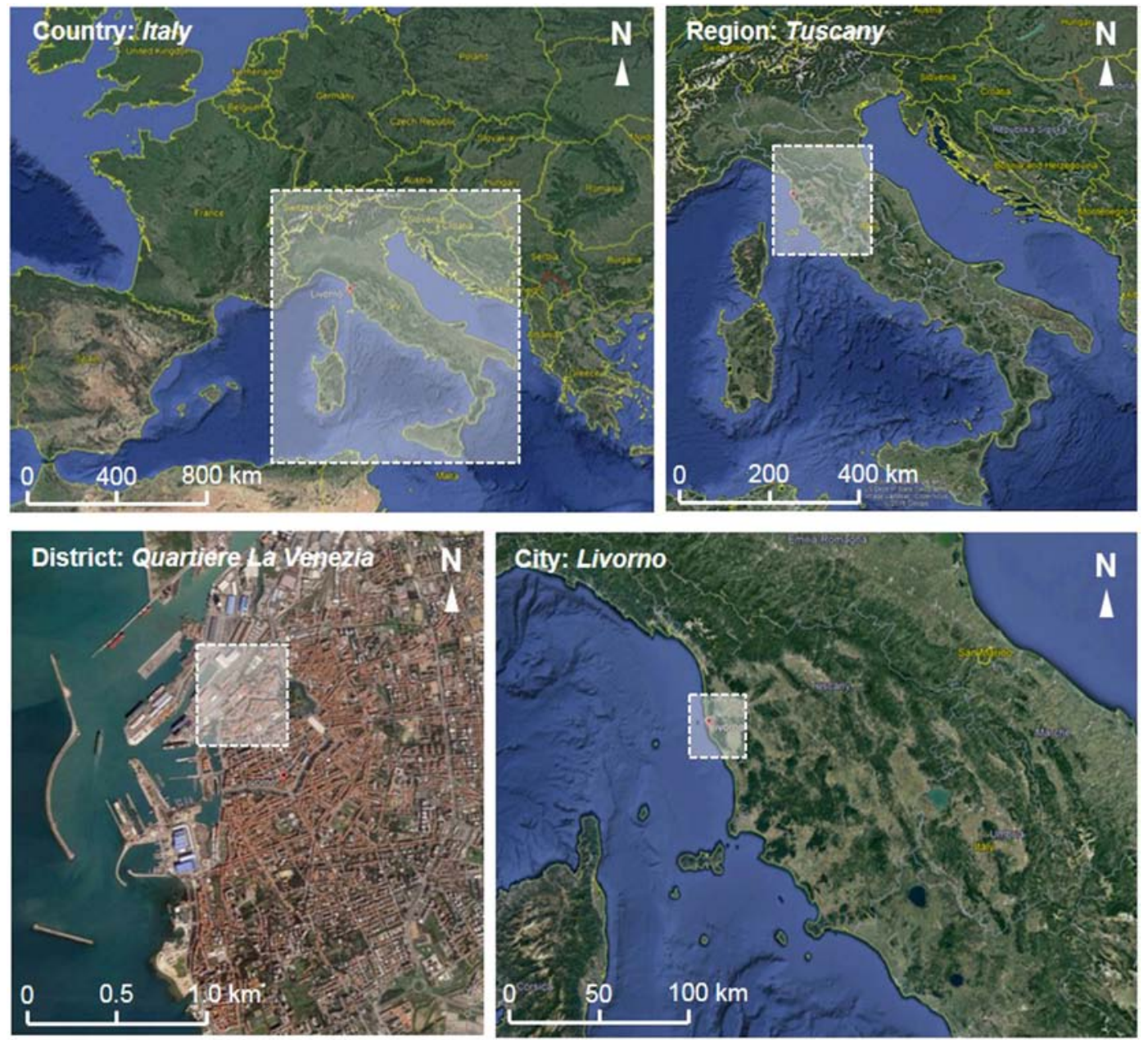

Fig. 1. Geographical location of the area of interest.

(Photo credit to Google Maps.)

The Port Authority of Livorno was a partner in the "Wind and Ports" (WP) and "Wind, Port, and Sea" (WPS) projects that included an anemometric monitoring network in four port areas in Italy (i.e. Savona, Genoa, La Spezia, Livorno) and two ports in France (i.e. Bastia and L'Ile Rousse), whose position is shown in Fig. 2a. The whole anemometric monitoring network currently comprises 31 ultrasonic anemometers, three weather stations (each one equipped with an ultrasonic anemometer, barometer, thermometer and hygrometer), and three LiDAR wind profilers. The anemometric monitoring network developed in the port area of Livorno consists of seven ultrasonic three-axial anemometers and one LiDAR wind profiler. Fig. $2 \mathrm{~b}$ shows the position of anemometers LIO3 and LIO6, as well as the LiDAR (LI51), which are the instruments that are placed closest upwind of Quartiere La Venezia with respect to the wind blowing from the sea, i.e. from the western sector.

The ultrasonic three-axial anemometers LIO3 and LIO6 measure the three components of the wind velocity vector at 20 and $12 \mathrm{~m}$ above
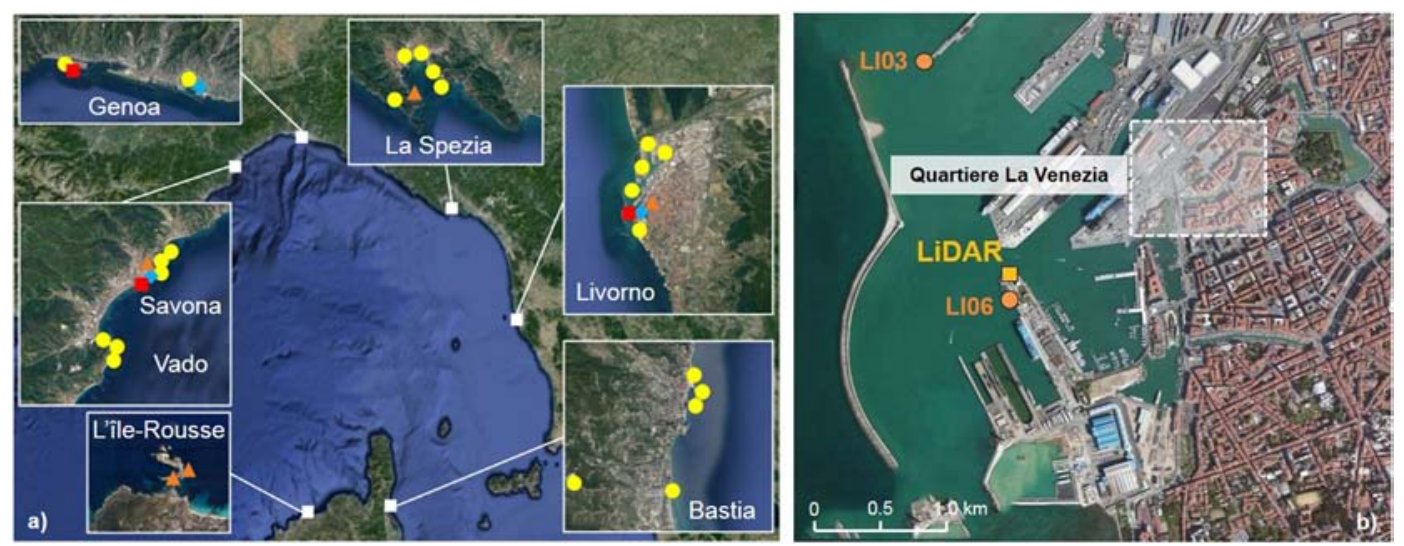

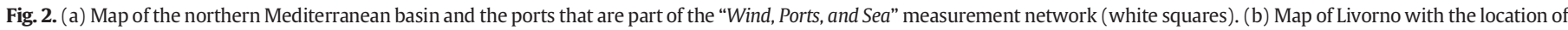

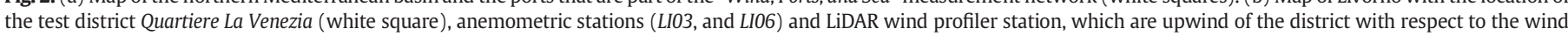
blowing from the sea. 
ground level (AGL), respectively, with a sampling rate of $10 \mathrm{~Hz}$ and a precision of $0.01 \mathrm{~m} / \mathrm{s}$. The LiDAR wind profiler, which is a WINDCUBE v2 Offshore pulsed LiDAR by Leosphere (http://www.leosphere.com/en/), measures the three components of the wind velocity vector at 12 heights above ground level from $40 \mathrm{~m}$ to $250 \mathrm{~m}$ with sampling rate of $1 \mathrm{~Hz}$. Table 1 summarizes the main characteristics of LIO3, LIO6, and LI51: LIO3 and LIO6 are still measuring since the date of their installation; LI51 was installed at the end of April 2015 and worked continuously for about 8 months. In December 2015 it stopped recording because of a vandalism attack.

The prevailing wind directions in the Port of Livorno correspond roughly to winds blowing from northeast and southwest, i.e. from land and sea. This is due to the orientation of the coastline, which is approximately from NNW to SSE, so that the western and eastern directions correspond to the prevailing land and sea breezes during summer. During winter, the prevailing winds are Libeccio (from southwest), Gregale (from northeast) and Sirocco (from southeast). Libeccio winds are the most intense ones, causing the strongest sea storms in this part of the Tyrrhenian Sea due to the long available fetch. Fig. $2 \mathrm{~b}$ shows that the position of the LiDAR wind profiler in the Port of Livorno with respect to Quartiere La Venezia is suitable to measure the undisturbed wind profiles approaching the investigated urban district for the Libeccio winds. Hence, the LiDAR wind profiler is expected to provide valuable information about the real inflow conditions useful for WT tests and/or CFD simulations, at least for wind directions in the range from $N W$ to $S W$. Therefore, the database of LI51 was analyzed in order to detect some Libeccio events to be used as inflow conditions for the CFD simulation of real sea storm situations, as described in the following section.

\section{Selection of neutral ABL conditions from LiDAR measurements}

The whole database of LiDAR measurements, from 29 April 2015 to 10 December 2015, was analyzed in order to detect Libeccio-like sea storm events. The raw database is composed of the three wind velocity components $(u, v, w)$, by means of which the mean horizontal and vertical wind components $\left(U_{u v}\right.$ and $\left.U_{w}\right)$, mean wind direction $(\alpha)$, maximum horizontal and vertical wind components ( $U_{u v, \max }$ and $U_{w, \max }$ ), gust wind factor $(G)$ and turbulence intensity $(I)$ of the three wind components $\left(I_{u}, I_{\mathrm{v}}\right.$ and $\left.I_{w}\right)$ averaged over a time of 10 min were systematically calculated. The selected events were expected to have logarithmic velocity profiles to be used as inflow conditions for the CFD simulations. From the statistical analyses, two events were selected corresponding to strong sea storms that occurred in the northern Tyrrhenian Sea: event 1 occurred from 1410 UTC on 27 July to 0450 UTC on 28 July 2015; event 2 occurred from 0010 UTC to 1630 UTC on 21 November 2015. In the following subsections, the events are briefly described from the meteorological and anemometric point of view.

\subsection{The sea storm on $27-28$ July 2015}

At the end of July, a low-pressure vortex named "Andreas" (according to the naming convention used by the Institute of Meteorology of the Freie Universität Berlin, Germany, http://www.met.fu-berlin.de/adopt-avortex/archiv/) moved from the east coast of the US across the Atlantic Ocean to central Europe. In the night between 27 and 28 July, Andreas' low pressure minimum of $995 \mathrm{hPa}$ was located above the North Sea.

Table 1

Main characteristics of the instruments shown in Fig. $2 \mathrm{~b}$ and their databases. Heights are the altitude above ground level (AGL) where measurements are taken (the range is reported for LI51). Install dates are in terms of quarters (Q1, Q2, Q3, Q4) of the year (YYYY)

\begin{tabular}{llllll}
\hline Id & Sensor & $\begin{array}{l}\text { Height } \\
{[\mathrm{m}] \text { AGL }}\end{array}$ & Location & $\begin{array}{l}\text { Sampling } \\
\text { rate }[\mathrm{Hz}]\end{array}$ & $\begin{array}{l}\text { Installation } \\
\text { date }\end{array}$ \\
\hline LI03 & 3D sonic anem. & 20 & Light tower & 10 & Q3-2010 \\
LI06 & 3D sonic anem. & 12 & Dock & 10 & Q3-2015 \\
LI51 & Pulsed LiDAR & $40-250$ & Dock & 1 & Q2-2015 \\
\hline
\end{tabular}

From the low core, an occluded front extended southward across Poland to Hungary, and from there further over Italy and southern France. A secondary low-pressure minimum developed in the lee of the western Alps during 27 July, which caused strong mistral winds over the Gulf of Lion and Libeccio winds over the Ligurian and Northern Tyrrhenian Sea. According to the simulations performed by means of the Weather Research and Forecasting (WRF) model initialized by the Global Forecast System (GFS) analyses, which is part of the wind forecast system of the WP and WPS projects (Repetto et al., 2017a), the surface wind speed (i.e. at $10 \mathrm{~m} \mathrm{AGL}$ ) reached a maximum around $20 \mathrm{~m} / \mathrm{s}$ to the north of Corsica Island on 28 July at 0200 UTC (Fig. 3); at the same time, the wind speed forecast at Livorno was slightly more than $10 \mathrm{~m} / \mathrm{s}$.

This sea storm event was measured by the LiDAR installed in the Port of Livorno (LI51). Fig. 4 shows the wind measurements recorded by the LiDAR LI51 during a 24-h ( $\left.T_{o b s}=1 \mathrm{~d}\right)$ period from 27 July at 1200 UTC and averaged over a time period of $10 \mathrm{~min}\left(T_{\text {aver }}=10^{\prime}\right)$. The following quantities are displayed in Fig. 4: the horizontal and vertical mean wind speed $\left(U_{u v}\right.$ and $\left.U_{w}\right)$, the mean wind direction (indicated by $N, N E$, $E, S E, S, N W, S W, W, N W)$, the mean wind gust factor $(G)$ and the mean longitudinal turbulence intensity $\left(I_{u}\right)$. Hereafter, for convenience, the adjectives "10-min average" and "mean" will be omitted when referring to the above mentioned variables of Fig. 4. During this period, the LiDAR recorded a wind blowing from the western quadrants all along the vertical profile up to $250 \mathrm{~m}$ AGL (top right panel in Fig. 4). On 27 July afternoon, approximately from 0200 UTC, the horizontal wind speed $\left(U_{u v}\right)$ started increasing above $10 \mathrm{~m} / \mathrm{s}$ and reached values higher than $15 \mathrm{~m} / \mathrm{s}$ around midnight (top left panel of Fig. 4), with peak wind speeds $\left(U_{u v(\max )}\right)$ up to about $20 \mathrm{~m} / \mathrm{s}$ (center left panel of Fig. 4) that determined values of the gust factor $(G)$ not larger than 1.5 (bottom left panel of Fig. 4) and longitudinal turbulence intensity values below 20\% (bottom right panel of Fig. 4). Note that the peak wind speed (left center panel of Fig. 4), conventionally defined as the wind speed averaged over $1 \mathrm{~s}$, coincides with the maximum measured value since the LiDAR samples at $1 \mathrm{~Hz}$. The vertical wind $\left(U_{w}\right)$ speed (center right panel of Fig. 4 ) is close to zero for the whole period, except close to the surface where values between 0.5 and $1 \mathrm{~m} / \mathrm{s}$ are measured when the horizontal wind speed $\left(U_{u v}\right)$ grows above $10 \mathrm{~m} / \mathrm{s}$. This is not a thermal effect, however, but it is most probably due to the location of LI51, with some low-rise buildings close to it. According to the measurements reported in Fig. 4, the sea storm duration was estimated between 1410 UTC on 27 July and 0450 UTC on the day after, which corresponds to slightly less than $15 \mathrm{~h}$. As shown in the polar diagrams of Fig. 5a, during this period, steadily from $240^{\circ} \pm 15^{\circ}$ (black marks). Fig. 5b and c shows the 10-min average (thin red lines) and 15-hour average (thick red line) of the measured wind speed $(U)$ and turbulent kinetic energy $(k)$ profiles, respectively. The wind speed profiles of Fig. $5 \mathrm{~b}$ are normalized with respect to the top wind speed $\left(U_{r e f}\right)$ measured at $250 \mathrm{~m}$ AGL, and reported on a logarithmic scale for the height $(z)$. That is the reason why the straight lines of this graph correspond to purely logarithmic profiles under neutral atmospheric stability conditions. For each wind speed profile, the friction velocity $\left(u^{*}\right)$ and roughness length $\left(z_{0}\right)$ values were inferred by fitting with the two-parameter logarithmic law-of-the-wall:

$U=\frac{u^{*}}{\kappa} \ln \left(\frac{z}{z_{0}}\right)$

From this analysis, it turned out that $u^{*}$ varied between 0.28 and $0.95 \mathrm{~m} / \mathrm{s}$ and $z_{0}$ between $10^{-1}$ and $10^{-4} \mathrm{~m}$, while the mean wind speed fitted profile showed a $u^{*}=0.59 \mathrm{~m} / \mathrm{s}$ and a $z_{0}=0.03 \mathrm{~m}$ over the whole 15-hour period. A value of 0.41 was assumed for the von Kármán constant $(\kappa)$. Fig. 5 c displays the 10-min average and 15-hour average turbulent kinetic energy profiles calculated from the LiDAR measurements:

$k(z)=\frac{1}{2}\left[\sigma_{u}^{2}(z)+\sigma_{v}^{2}(z)+\sigma_{w}^{2}(z)\right]$ 


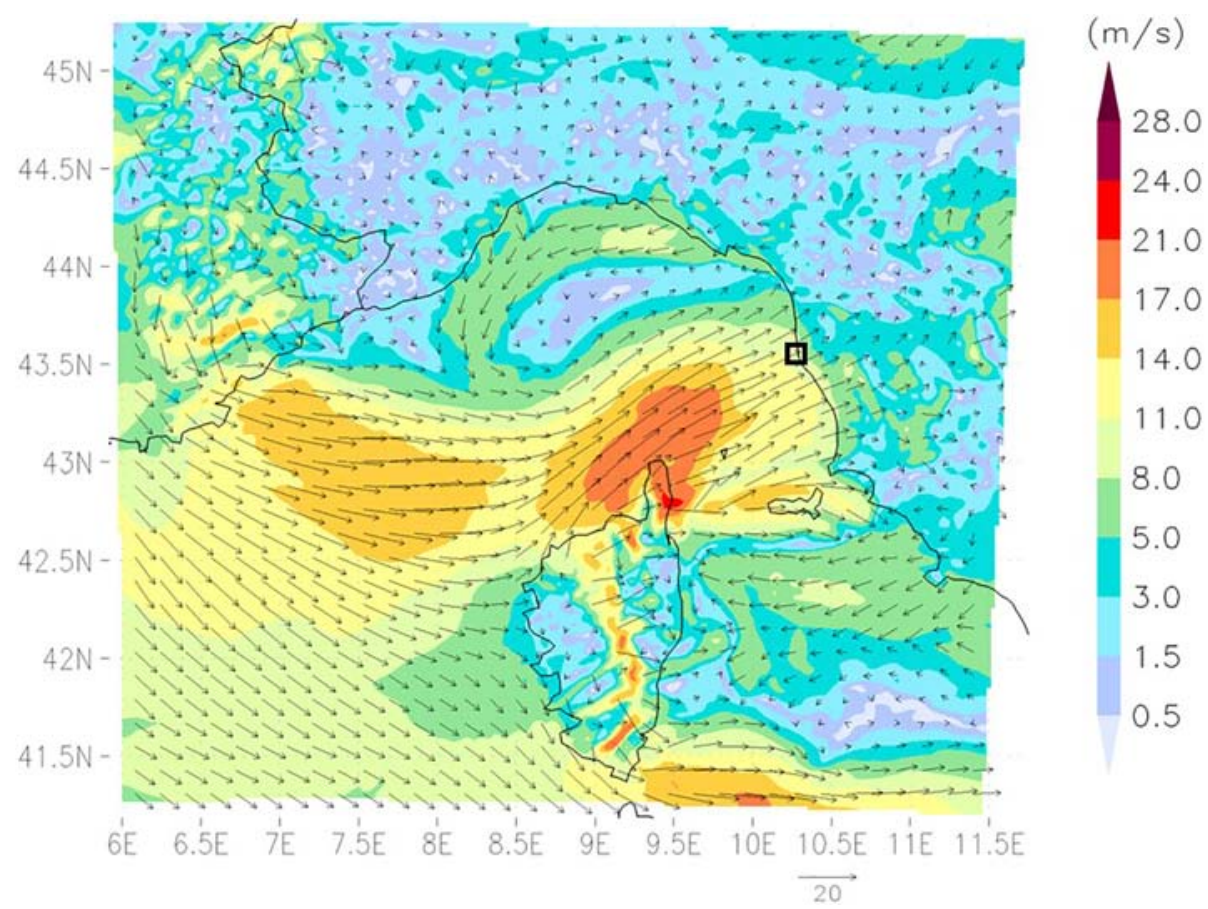

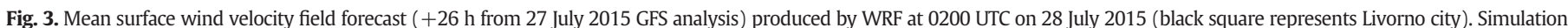

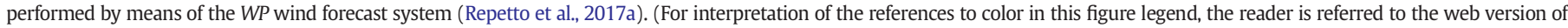
this article.)

where $\sigma_{u}(z), \sigma_{v}(z), \sigma_{w}(z)$ are the standard deviations of the wind speed components $(u, v$ and $w)$. Each $k$ profile was normalized with the square of the corresponding friction velocity $\left(u^{*}\right)$ value.
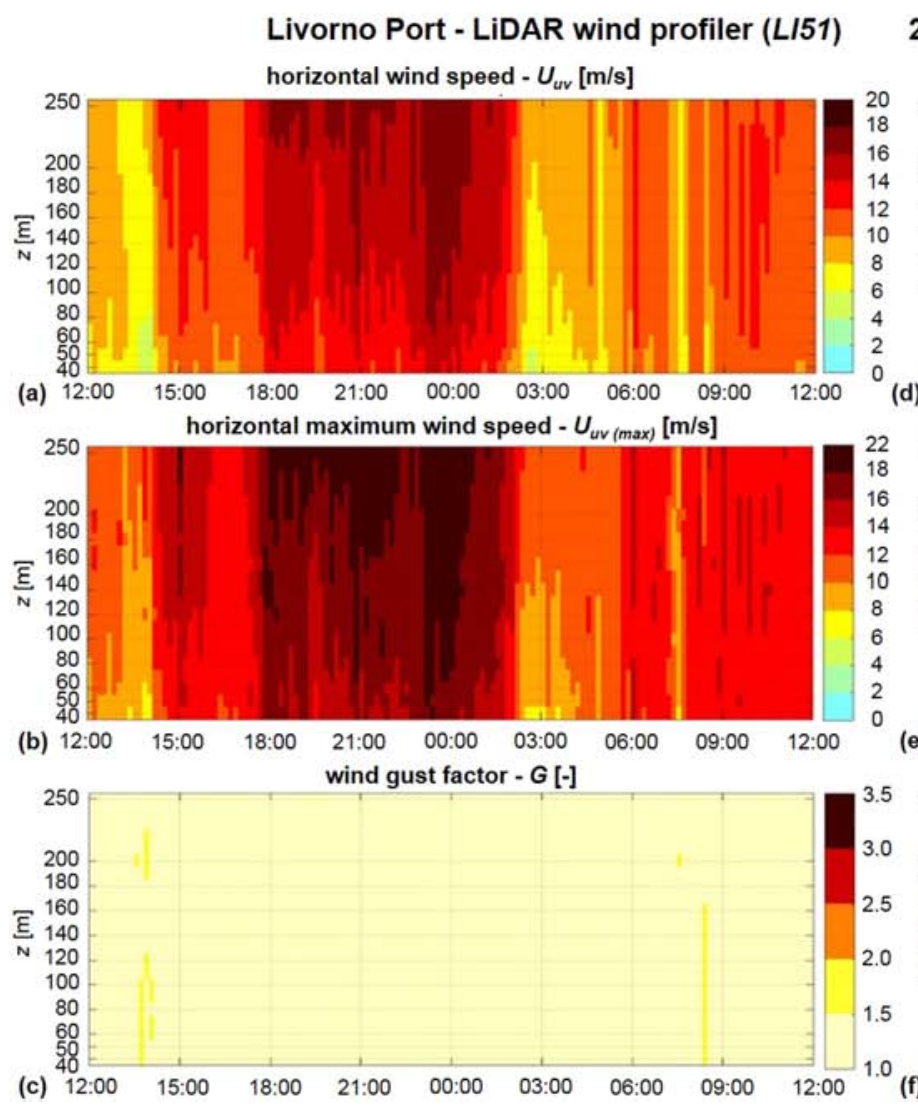

\subsection{The sea storm on 21 November 2015}

On 19 November 2015, the rapidly developing low-pressure system, named "Kunibert", was present southwest of Ireland. Situated south of
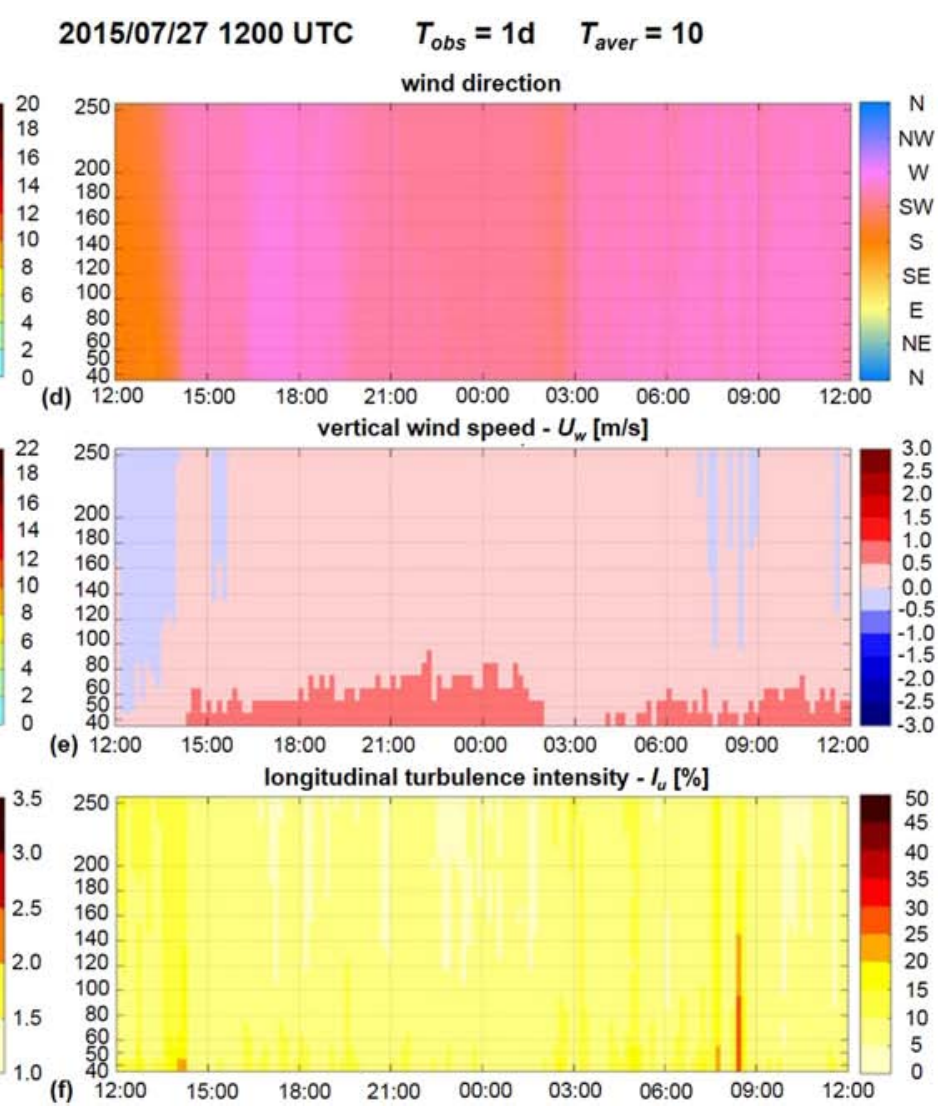

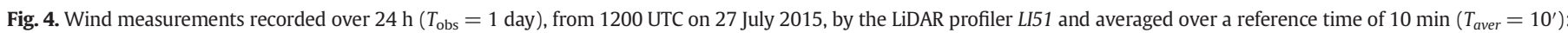
(a) horizontal wind speed, (b) horizontal maximum wind speed, (c) wind gust factor, (d) wind direction, (e) vertical wind speed, (f) longitudinal turbulence intensity. 


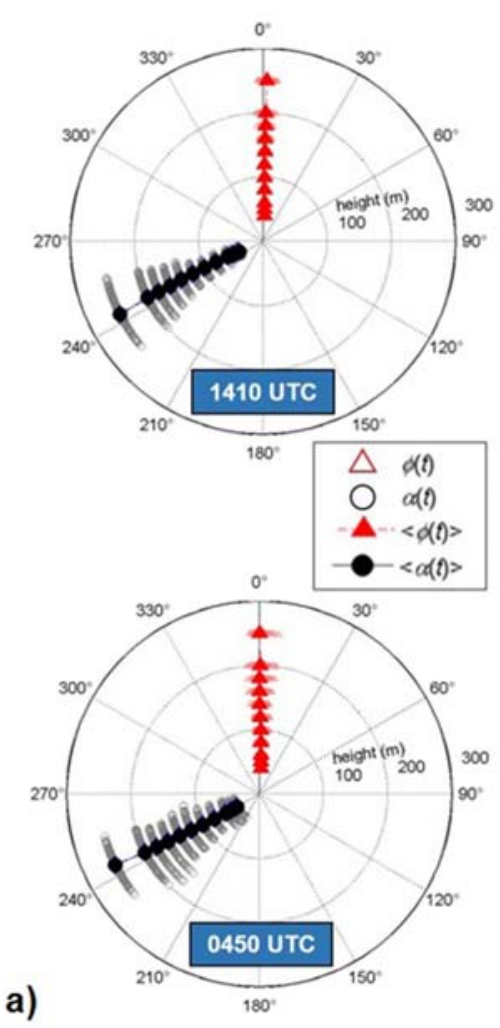

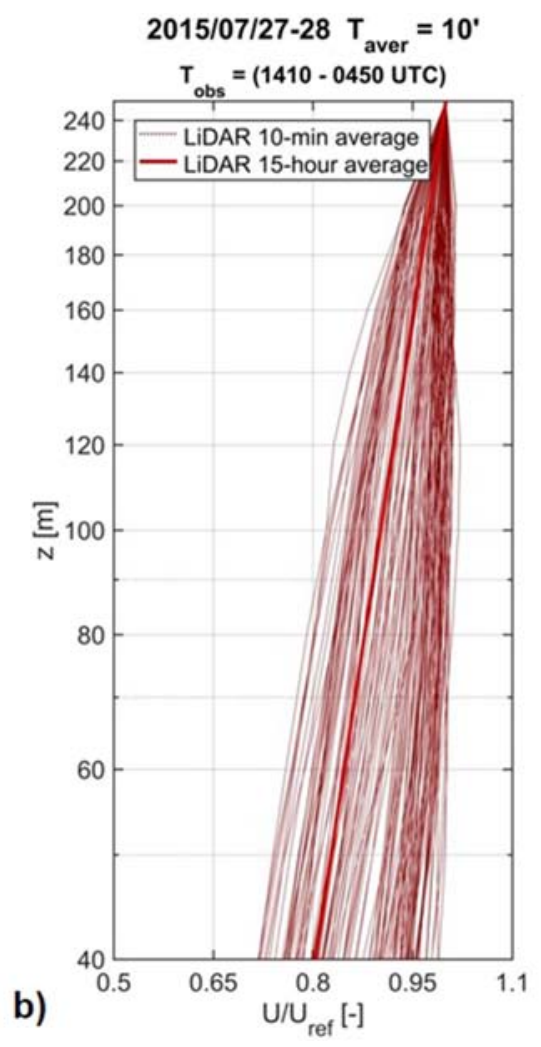

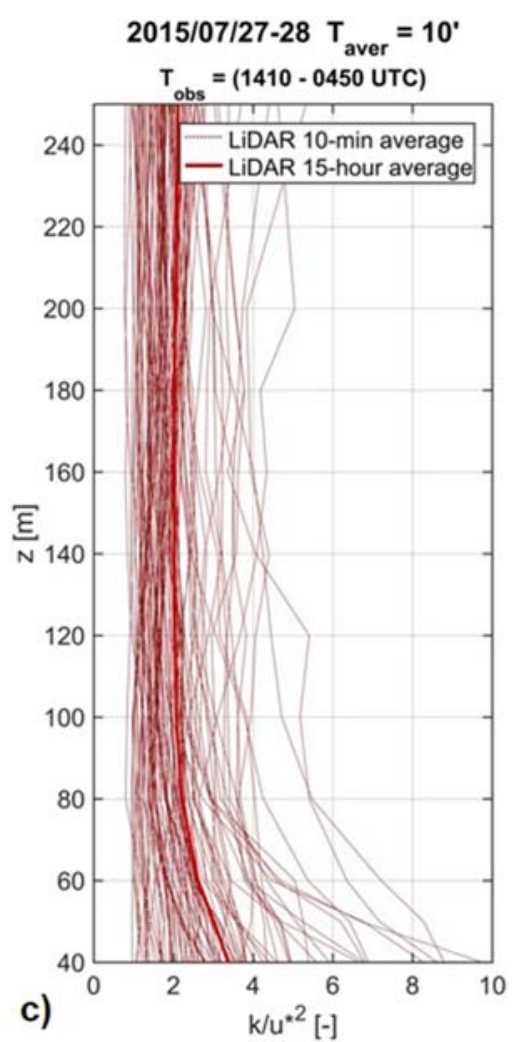

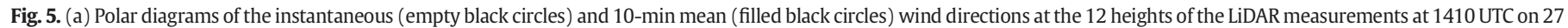

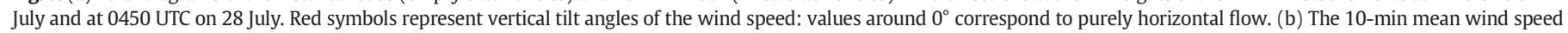

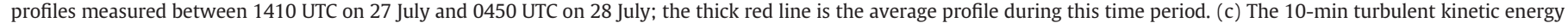

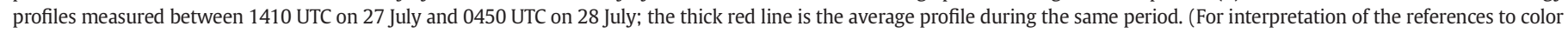
in this figure legend, the reader is referred to the web version of this article.)

Kunibert, the high-pressure "Viva", with a maximum of $1032 \mathrm{hPa}$, was stationary over central Spain determining fair weather conditions all over the western Mediterranean. During the day, Viva began shifting south-westward while the low-pressure Kunibert began spreading over France causing cloudy and rainy weather. On 20 November, anticyclone Viva was at a pressure of about $1037 \mathrm{hPa}$ only to the east of the Azores, and the Kunibert's cold front crossed Spain and France, reaching the western Alps during the night. On 21 November, cyclone Kunibert had strengthened strongly and moved further to the west reaching a minimum of $995 \mathrm{hPa}$ over Hungary. At the lee side of the Alps, a secondary pressure minimum over the Gulf of Genoa caused a strong Libeccio wind over the Ligurian Sea and northern Tyrrhenian Sea during the whole day. The surface wind field forecast by WRF on 21 November at 0400 UTC is reported in Fig. 6, which shows wind speed values higher than $25 \mathrm{~m} / \mathrm{s}$ over the main ridges of Corsica and over the sea between Corsica and Tuscany.

Analogously to Fig. 4, Fig. 7 shows the wind measurements recorded by the LiDAR profiler LI51 during a 24-h period $\left(T_{o b s}=1 \mathrm{~d}\right)$ from 21 November at 0000 UTC and averaged over a period time of $10 \mathrm{~min}\left(T_{\text {aver }}=\right.$ $10^{\prime}$ ). Between 0000 UTC and 1700 UTC, the LiDAR recorded wind blowing from the western quadrants all along the vertical wind profile up to $250 \mathrm{~m}$ AGL (top right panel in Fig. 7). In the same period of time, the wind speed was always above $10 \mathrm{~m} / \mathrm{s}$, except in a short interval around $0800 \mathrm{UTC}$, and above $20 \mathrm{~m} / \mathrm{s}$ at around 0300, 0900, and 1500 UTC (top left panel of Fig. 7). The peak wind was always higher than $20 \mathrm{~m} / \mathrm{s}$ (center left panel of Fig. 7), except around 0800 UTC. The wind gust factor was always below 1.5 (bottom left panel of Fig. 7) and the longitudinal turbulence intensity displayed values below 20\% (bottom right panel of Fig. 7), again except around 0800 UTC. The vertical wind speed (center right panel of Fig. 7) is close to zero for the whole period, or between 0.5 and $1 \mathrm{~m} / \mathrm{s}$ close to the surface. Note that, after the sea storm had ceased, the wind veered from east and it started raining, which created downdraft as demonstrated by the strong negative vertical wind speed that occurred after 1800 UTC (center right panel of Fig. 7). The polar diagram of Fig. 8a shows that from 0010 UTC to 1630 UTC on 21 November, the wind direction (black symbols) was stationary from $240^{\circ} \pm 15^{\circ}$. Fig. $8 \mathrm{~b}$ and $\mathrm{c}$ shows the 10-min average (thin blue lines) and 16-hour average (thick blue line) of the measured speed $(U)$ and turbulent kinetic energy $(k)$ profiles, respectively. As showed in Section 3.1 for the sea storm on 27-28 July 2015 , also for the current storm the 10 -min average wind speed profiles were fitted to the logarithmic law of Eq. (1). The fit showed that the parameters $u^{*}$ and $z_{0}$ varied between 0.31 and $1.03 \mathrm{~m} / \mathrm{s}$ and $10^{-1}$ and $10^{-6} \mathrm{~m}$, respectively. The mean wind speed fitted profile provided $u^{*}=0.68 \mathrm{~m} / \mathrm{s}$ and $z_{0}=0.001 \mathrm{~m}$ over the whole 16-hour period.

\section{Wind-tunnel tests}

Wind-tunnel (WT) tests were performed on a reduced-scale model (1:300) of the district of Livorno city (Italy), called "Quartiere La Venezia", in the WT facility of the Department of Civil, Chemical, Environmental Engineering (DICCA) of the Polytechnic School of the University of Genoa, Italy (Fig. 9). The WT test section has the following dimensions: $1.70 \mathrm{~m}$ (width) $\times 1.35 \mathrm{~m}$ (height) $\times 8.8 \mathrm{~m}$ (length). The reader can refer to the previous publication (Ricci et al., 2017a) for additional information. In particular, urban wind flows occurring in the district when strong winds blow from the sea (i.e. during sea storm conditions) were investigated. According to the statistical analysis of the anemometric measurements of LIO3 and LIO6, the westerly wind directions are associated with the strongest winds in Livorno, indeed. Therefore, three reference wind directions ( $W S W, W$ and $W N W$ ) representative of a specific ABL condition were reproduced in the WT. The 


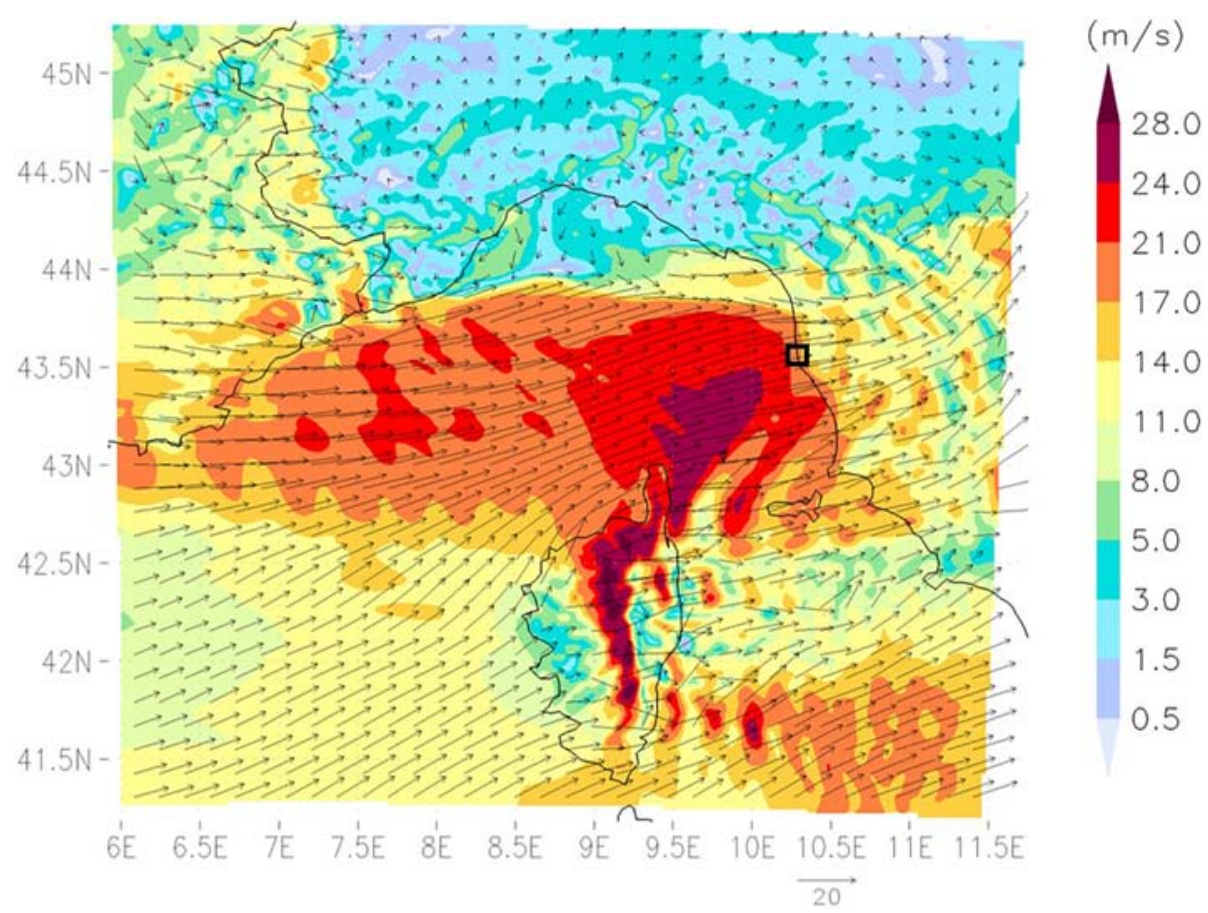

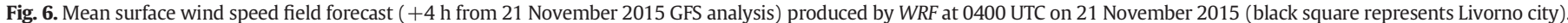

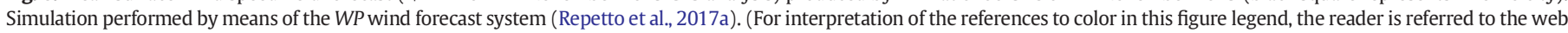
version of this article.)

aerodynamic roughness length $\left(z_{0}=0.1 \mathrm{~m}\right.$ at full scale) was determined by the digital map of land cover types of the CORINE project (Bossard et al., 2000). The CORINE database describes the terrain in

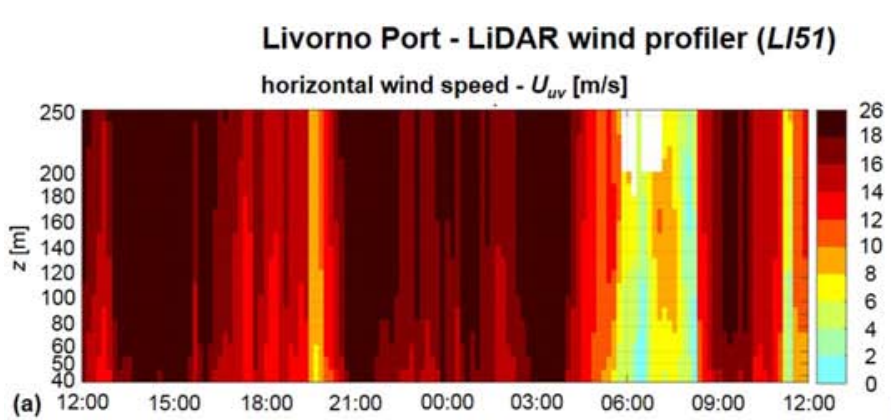

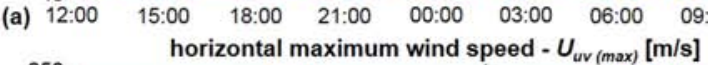
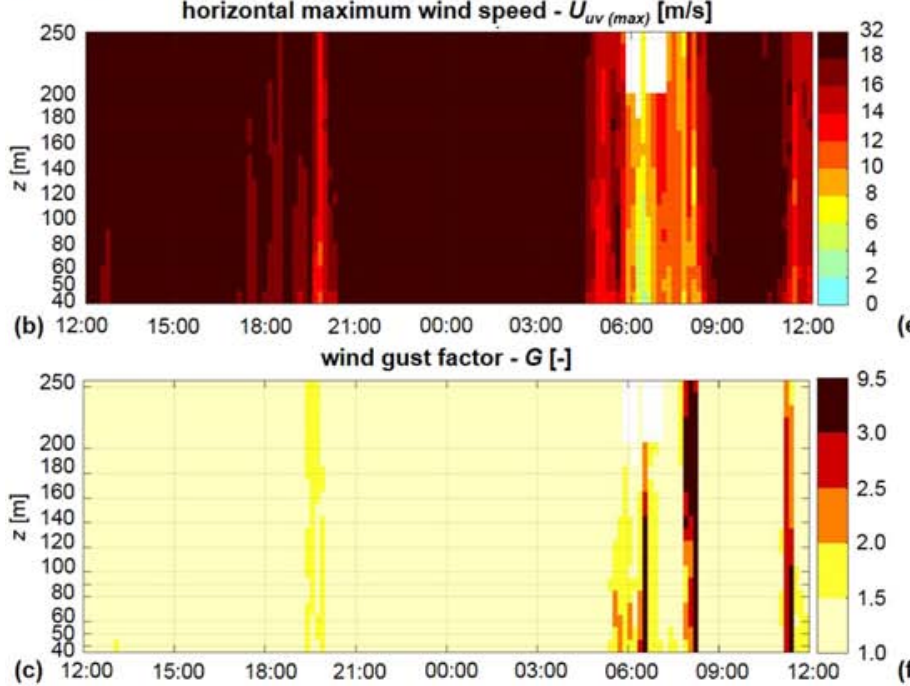

terms of soil types, which in turn can be related to the corresponding aerodynamic roughness lengths (Wieringa, 1976; Stull, 1988). Fig. 9 shows the physical model of the area under investigation, realized in
$2015 / 11 / 210000$ UTC $\quad T_{\text {obs }}=1 \mathrm{~d} \quad T_{\text {aver }}=10$

wind direction
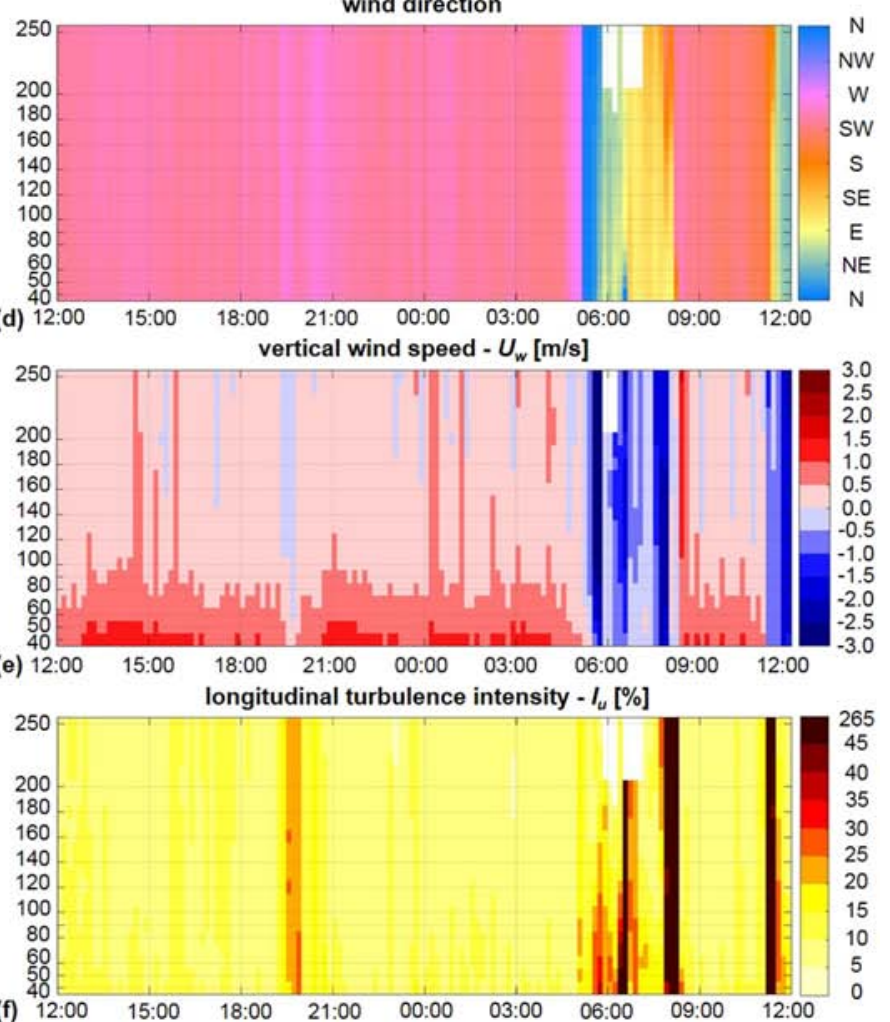

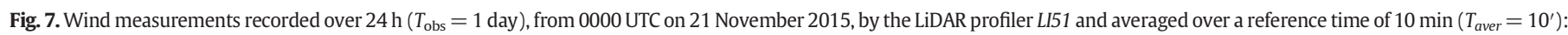
(a) horizontal wind speed, (b) horizontal maximum wind speed, (c) wind gust factor, (d) wind direction, (e) vertical wind speed, (f) longitudinal turbulence intensity. 

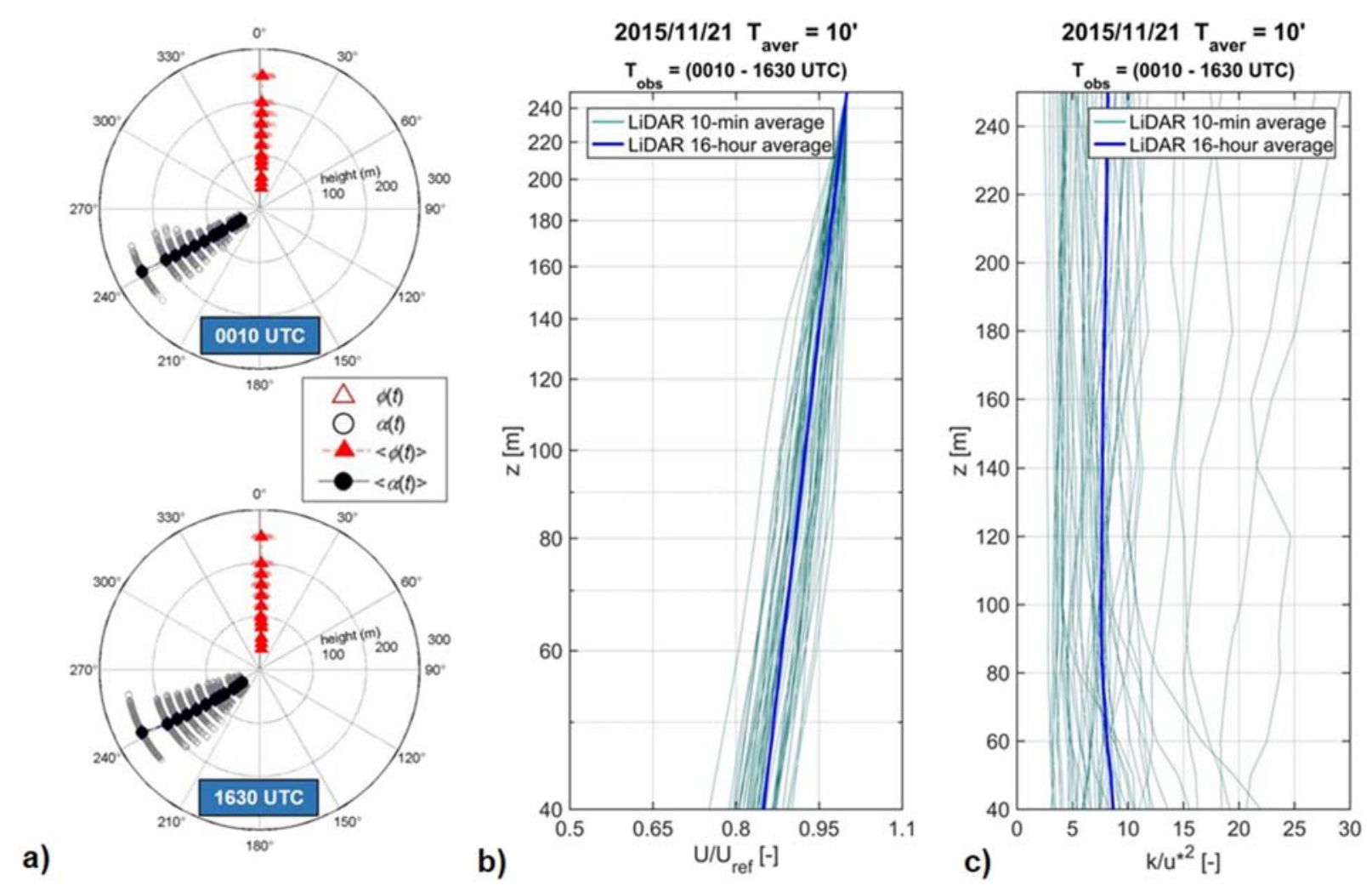

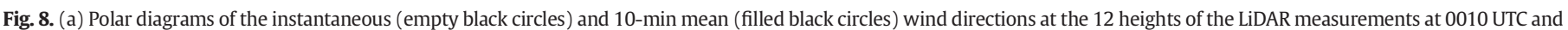

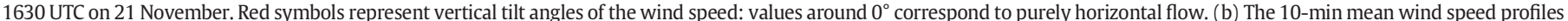

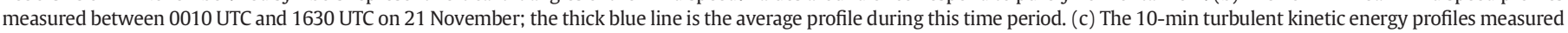

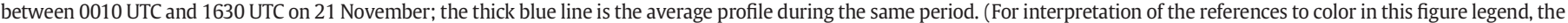
reader is referred to the web version of this article.)

medium-density fiberboard for plates and buildings and closed-cell PVC foamboard panels for roofs and bridges.

Mean wind speed $(U)$ and turbulence intensity $(I)$ profiles were measured by means of a multihole pressure probe (i.e. Cobra probe), from $0.02 \mathrm{~m}$ to 0.6 above the ground level, throughout the whole district on a Cartesian grid of 15 positions $\left(\mathrm{L}_{1-5}, \mathrm{~L} 2_{1-5}, \mathrm{~L} 3_{1-5}\right)$ and at 10 positions $\left(\mathrm{A} 1_{1}-\mathrm{A} 5_{2}\right)$ chosen along the water canal called "Canale Rosciano" (Fig. 10a, b). An ABL of about $0.6 \mathrm{~m}$, with a mean wind speed of about $17 \mathrm{~m} / \mathrm{s}$ at gradient height, was measured at the end of the fetch of roughness (of about $7.5 \mathrm{~m}$ ) in the middle of the cross-section and approximately $1 \mathrm{~m}$ upstream of the first building of the urban model. The ABL height was found to be four and six times larger than the maximum (i.e. $0.15 \mathrm{~m}$ ) and the mean (i.e. $0.1 \mathrm{~m}$ ) height of the buildings, respectively. In the present study only the reference wind direction WSW $\left(\alpha=240^{\circ}\right.$ ) was analyzed, so that the results obtained for reference wind directions $W\left(\alpha=270^{\circ}\right)$ and $W N W\left(\alpha=300^{\circ}\right)$ will not be used here.

\section{CFD simulations}

\subsection{Computational domain and grid}

A high-resolution computational grid of Quartiere La Venezia was realized at the same scale of 1:300 as the WT tests. The size of the domain was $L \times W \times H=5.5 \times 1.70 \times 1.35\left(\mathrm{~m}^{3}\right)$, where the width $(W)$ and height $(H)$ are coincident with the WT cross-section while the length $(L)$ represented (a portion of) the WT test-section length. The inlet face of the computational domain was placed where the approachflow profiles (in terms of mean wind speed and turbulence intensity) were measured in the WT section, approximately $1 \mathrm{~m}$ upstream of the
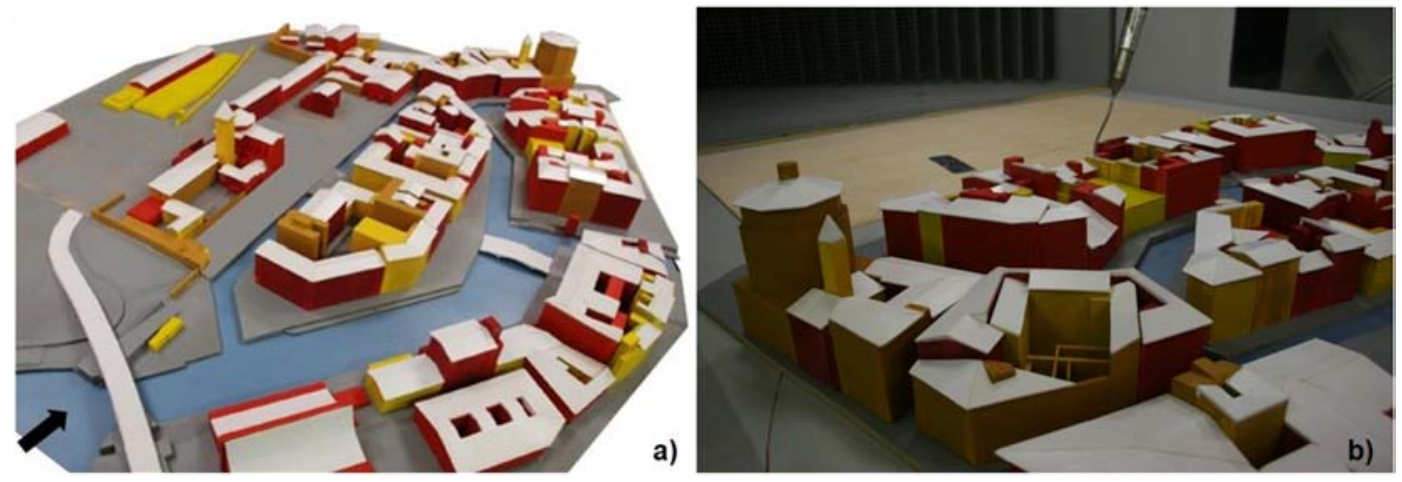

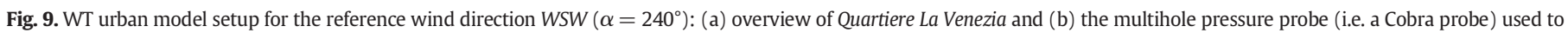
measure wind speed and direction during the tests. 

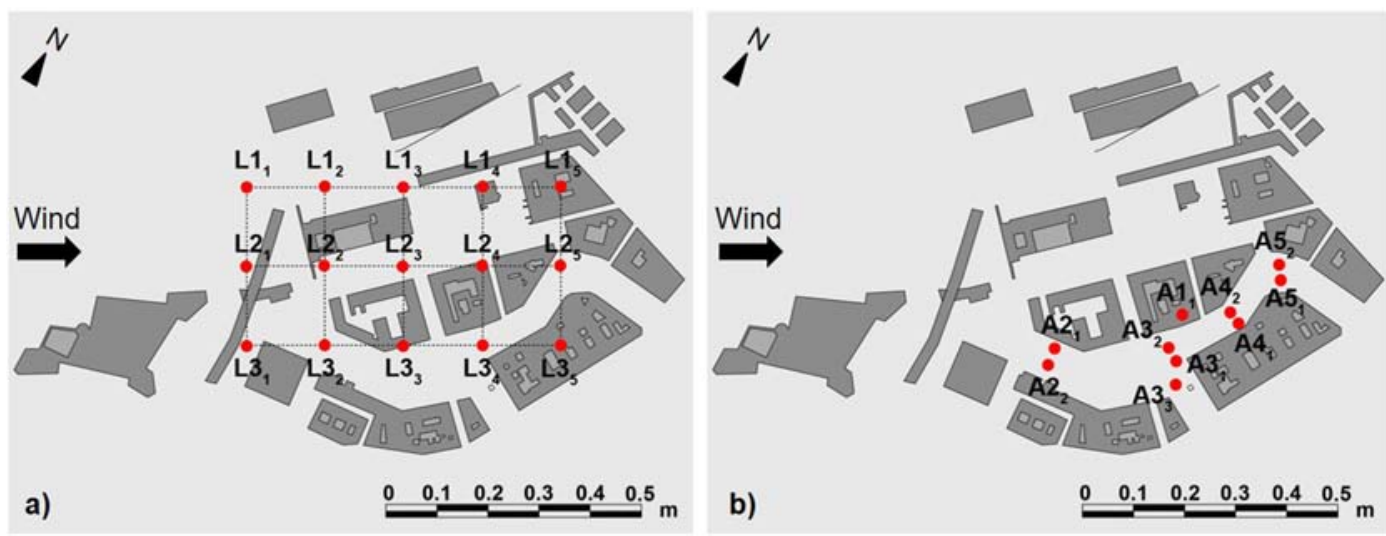

Fig. 10. Location of measurement positions (a) $\left(\mathrm{L} 1_{1-5}, \mathrm{~L} 2_{1-5}, \mathrm{~L} 3_{1-5}\right)$ and (b) $\left(\mathrm{A} 1_{1}-\mathrm{A} 5_{2}\right)$ in the investigated district of Livorno city.

first building of the urban model. Both the upstream and the downstream parts of the computational domain, with respect to the position of the urban model, are in accordance with best practice guidelines (Franke et al., 2007; Tominaga et al., 2008). Indeed, the distance between the inlet face and the first building of the urban model, and the distance between the last building of the urban model and the outlet face are larger than 5 and 15 times the maximum height of the buildings $\left(h_{\mathrm{b}}=0.15 \mathrm{~m}\right)$, respectively. The same computational domain was also used by Ricci et al. (2017b, 2018), when analyzing the impact of geometrical simplifications applied to the reduced-scale urban district (Ricci et al., 2017b) and the impact of inflow conditions (Ricci et al., 2018), respectively. In particular in (Ricci et al., 2017b), two computational grids (simplified and approximated geometrical models) consistent with two levels of refinement of the physical geometry used for the WT were constructed in order to determine to what extent the buildings can be simplified without loss of reliability of the numerical results both in terms of mean wind speed and turbulence intensity. 3D steady RANS simulations with the realizable $k-\varepsilon$ turbulence model (Shih et al., 1995) carried out on the two CFD cases showed that the best compromise turned out to be using building geometries with their real ground plans and heights but replacing pitched roofs with flat ones, such as the approximated geometrical model. In that regard, the approximated geometrical model consisted of a high-resolution computational grid constructed using the grid-generation technique proposed by van Hooff and Blocken (2010) and adhering to the best practice guidelines (Blocken, 2015; Franke et al., 2007; Tominaga et al., 2008) (Fig. 11). The minimum near-wall cell size on the ground floor, buildings and bridges was defined equal to $0.0033 \mathrm{~m}$ in order to obtain dimensionless wall unit values $y^{+}$(i.e. $y^{+}{ }_{a v g}=101.20$ ) in the logarithmic layer range, i.e. 30-300 (Blocken et al., 2007a, 2007b). In order to maximize the numerical accuracy and avoid converge problem when using the required second-order discretization schemes, only hexahedral and prismatic control volumes were constructed. The resulting computational grid consisted of 23.2 million control volumes.

\subsection{Boundary conditions}

Three sets of inflow conditions - in terms of mean wind speed $(U)$, turbulent kinetic energy $(k)$ and turbulence dissipation rate $(\varepsilon)$ profiles were imposed separately at the inlet face: the so-termed WT profile set,
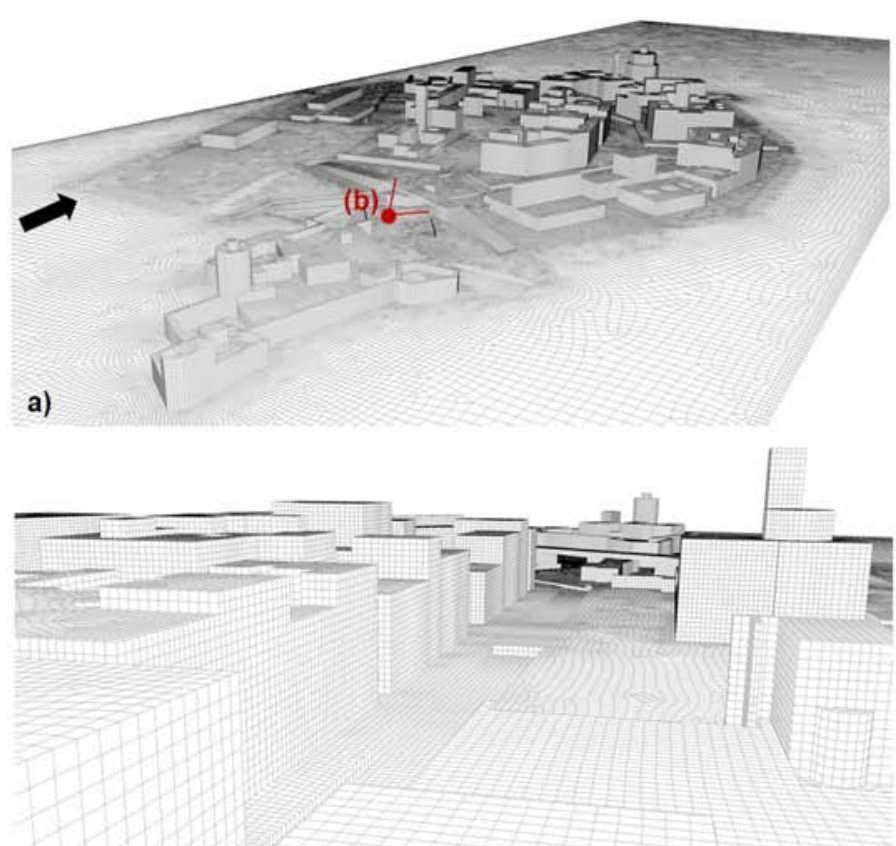
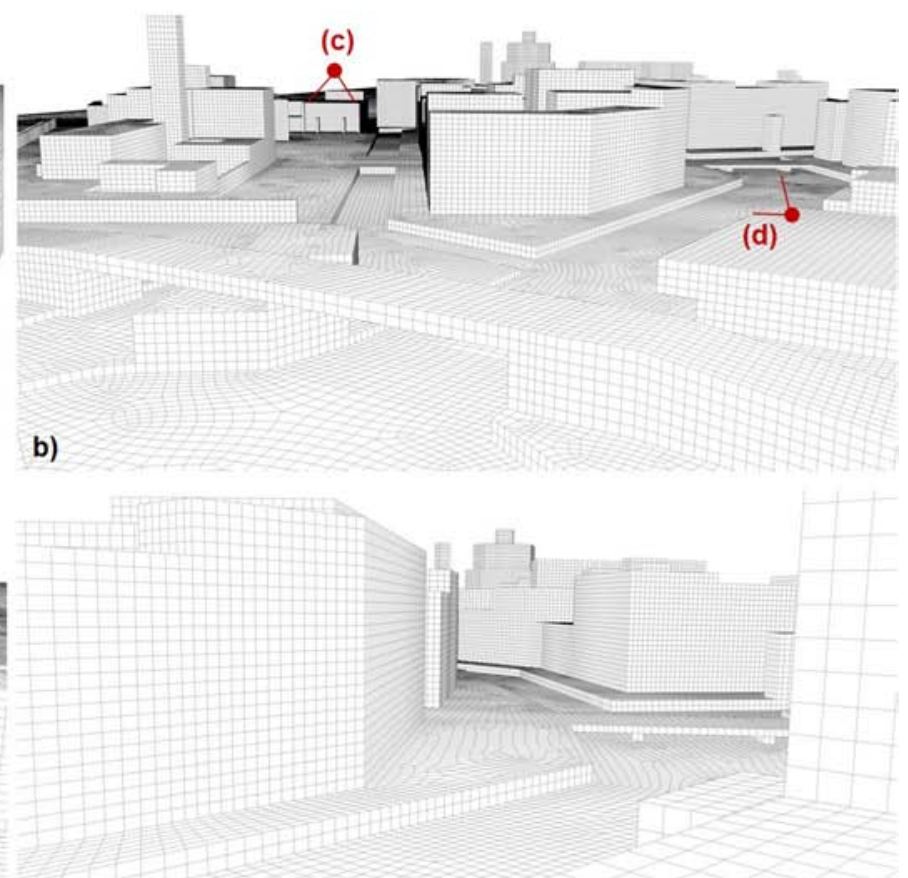

c)

Fig. 11. Perspective view of the computational grid for the reference wind direction WSW $\left(\alpha=240^{\circ}\right)$. 
consistent with the approach-flow profiles (mean wind speed and turbulence intensity) in the WT tests; the LiDAR profile 1 set corresponding to the meteorological event 1 (sea storm on 27-28 July 2015) described in Section 3.1, and the LiDAR profile 2 set corresponding to the meteorological event 2 (sea storm on 21 November 2015) described in Section 3.2. Fig. 12a shows the mean speed $(U)$ profiles applied at the inlet face of the computational domain and normalized with the reference speed $\left(U_{r e f}\right)$ value measured at $0.9 \mathrm{z} / \mathrm{H}$, where $H$ is equal to the height of the computational domain. Fig. 12b shows the turbulent kinetic energy $(k)$ profiles normalized with respect to the square of the corresponding friction velocity $\left(u^{*}\right)$ value: $0.89 \mathrm{~m} / \mathrm{s}$ (with a $z_{0}=0.1 \mathrm{~m}$ ) for the $W T$ profile, $0.59 \mathrm{~m} / \mathrm{s}$ (with a $z_{0}=0.03 \mathrm{~m}$ ) for the LiDAR profile 1 (i.e. obtained fitting the 15-hour average wind profile with a logarithmic law) and $0.68 \mathrm{~m} / \mathrm{s}$ (with a $z_{0}=0.001 \mathrm{~m}$ ) for the LiDAR profile 2 (i.e. obtained fitting the 16-hour average wind profile). Fig. 12c shows the turbulence dissipation rate $(\varepsilon)$ profiles normalized with the ratio $u^{* 3} / \lambda$, where $\lambda$ represents a characteristic length scale which was taken equal to the height $H$ of the computational domain.

The so-termed WT profile set was calculated by linearly interpolating the WT data collected approximately $1 \mathrm{~m}$ upstream of the first building of the urban model at 15 positions along three vertical lines L1-L1', L2L2' and L3-L3' (Fig. 13). Due to the limitations in the movement of the traverse system, the ABL profiles (i.e. mean wind speed and standard deviations of the wind speed fluctuations) were measured in the range 0 and $0.44 z / H$ (i.e. from 0.02 to $0.60 \mathrm{~m}$ ) at 15 different heights using the Cobra probe (Fig. 12). Nevertheless, in order to reproduce the WT flow development throughout the computational domain (i.e. a portion of WT test section), mean wind speed and standard deviations of wind speed fluctuations $\left(\sigma_{u}, \sigma_{v}, \sigma_{w}\right)$ were measured at 8 different heights by means of a boundary-layer rake (Barlow et al., 1999) near the top wall of the WT in the range $0.9-1.0 \mathrm{z} / \mathrm{H}$. In the remaining range $0.44-0.9 z / H$, mean speed values and the wind speed standard deviations were linearly interpolated in order to link the two measured parts above mentioned. Overall, for the WT profile, three different mean wind speed $(U)$ profiles were found along the three lines (L1L1', L2-L2' and L3-L3') showing a slight non-uniformity of the ABL, of about $4 \%$ from 0.02 to $0.60 \mathrm{~m}$ above the ground level, in the span-wise direction upstream of the urban model. Fig. 12 shows the WT data and the WT profiles referred to as L2-L2'. Ricci et al. (2018) showed that the span-wise gradients in the inlet profiles do not affect the wind flows within the given urban canopy, so that they can be neglected without loss of reliability of the numerical calculations. The reader can refer to Ricci et al. (2018) for further information. A similar nonuniformity was found also in terms of turbulent kinetic energy $k(z)$ and turbulence dissipation rate $(\varepsilon)$ profiles. The $\varepsilon$ profile was calculated using the measured wind speed standard deviations $\sigma_{u}(z), \sigma_{v}(z), \sigma_{w}(z)$ through Eq. (3) (Tominaga et al., 2008):

$\varepsilon(z)=C_{\mu}^{0.5} k(z) \frac{d U}{d z}$

where $d U / d z$ is the vertical gradient of the mean speed and the constant $C_{\mu}$ is assumed equal to 0.09 .

As far as the LiDAR profile 1 and LiDAR profile 2 are concerned, the mean wind speed profiles (red and blue lines, respectively, in Fig. 12) obtained by fitting the logarithmic law to the LiDAR data were imposed at the inlet face of the computational domain from 0 to $0.9 z / H$. Above $0.9 \mathrm{z} / \mathrm{H}$ the boundary layer near the wall top of the WT was calculated according to Eq. (4) proposed by Fox et al. (1998):

$\frac{U}{U_{\infty}}=\left[2\left(\frac{z}{h_{\mathrm{BL}}}\right)-\left(\frac{z}{h_{\mathrm{BL}}}\right)^{2}\right]$

where $U_{\infty}$ is the geostrophic mean wind speed at $0.9 \mathrm{z} / \mathrm{H}$, and $h_{\mathrm{BL}}$ is the boundary-layer thickness assumed equal to $0.1 \mathrm{z} / \mathrm{H}$, i.e. $0.135 \mathrm{~m}$, analogously to WT profile set. For the sake of simplicity, a constant- $k$ profile
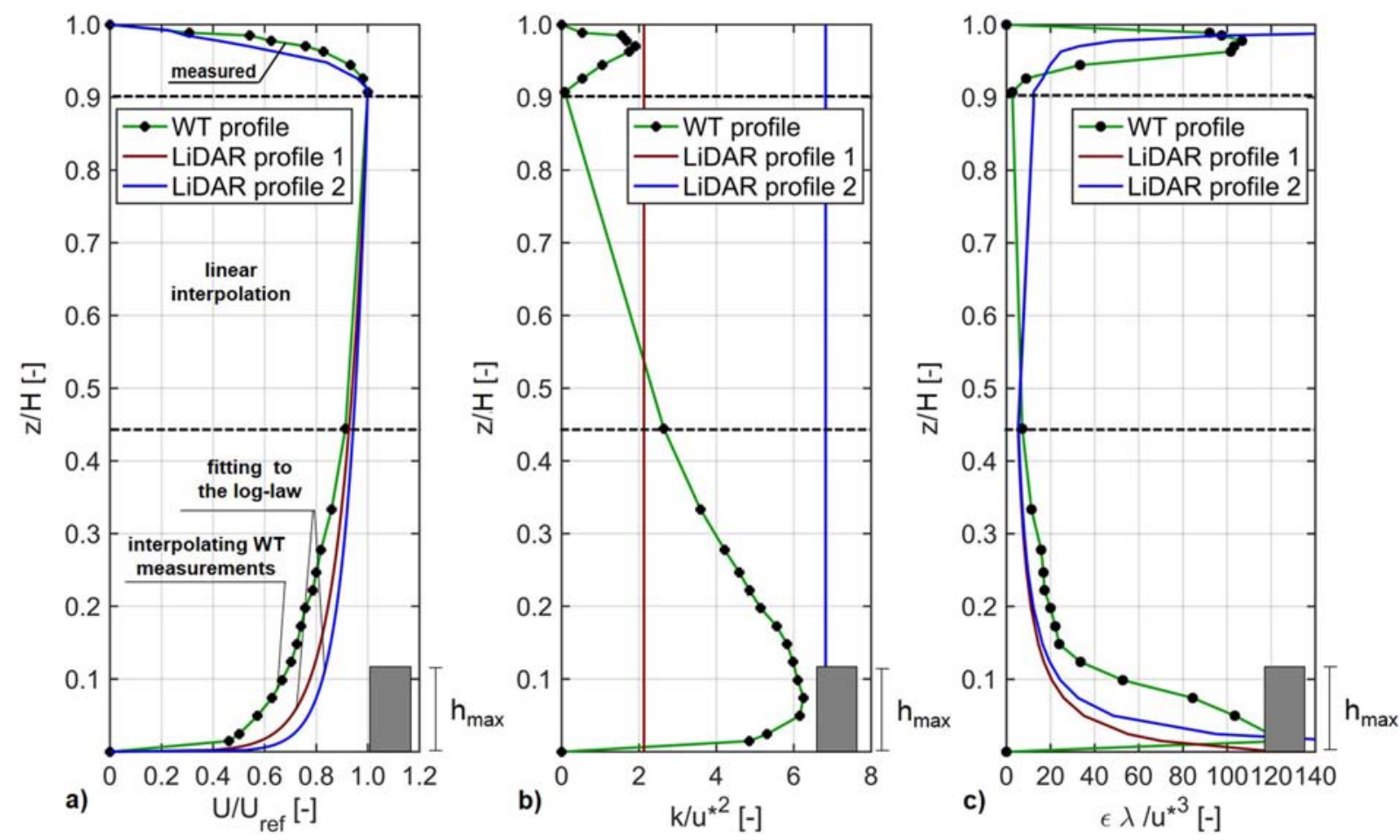

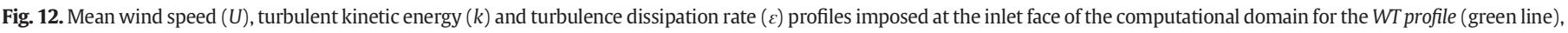

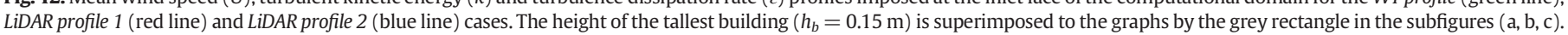
(For interpretation of the references to color in this figure legend, the reader is referred to the web version of this article.) 


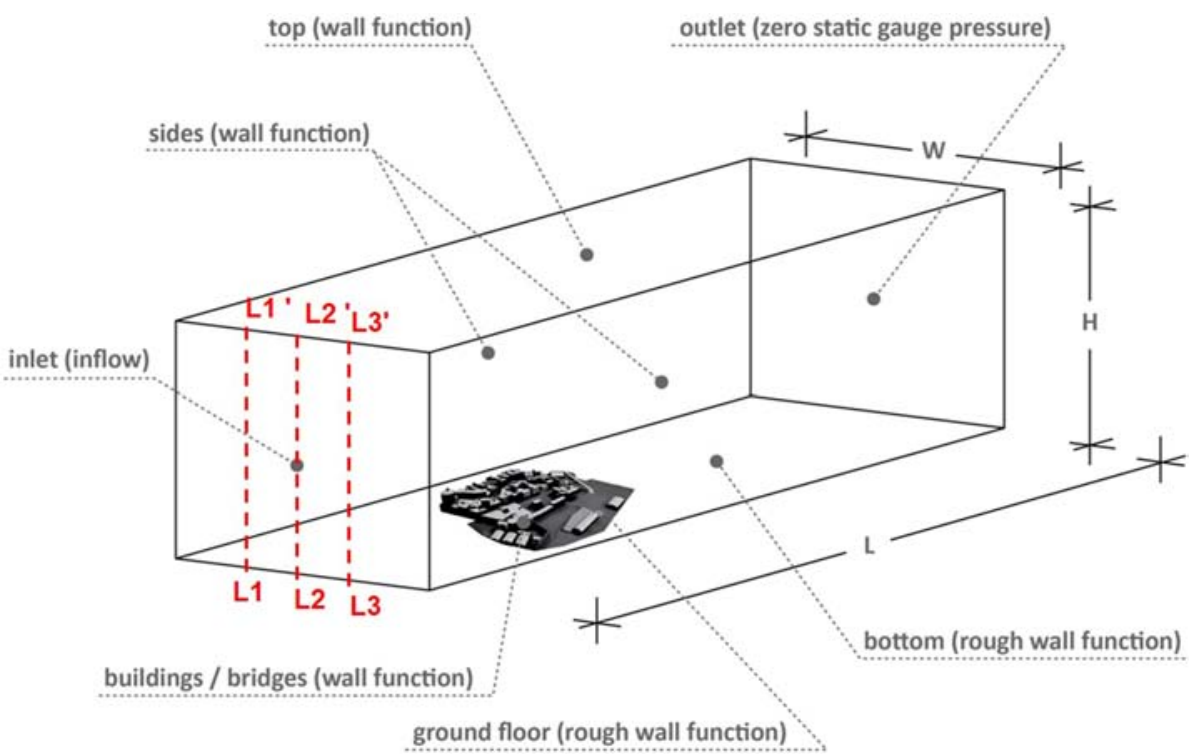

Fig. 13. Boundary conditions of the computational domain.

obtained by averaging the $k(z)$ values shown in Figs. 5 and 8 was imposed at the inlet face. Finally, the turbulence dissipation rate $\varepsilon(z)$ profiles were calculated by Eq. (5) (Richards and Hoxey, 1993):

$\varepsilon(z)=\frac{\left(u^{*}\right)^{3}}{\kappa\left(z+z_{0}\right)}$

where $u^{*}$ and $z_{0}$ are equal to $0.59 \mathrm{~m} / \mathrm{s}$ and $0.03 \mathrm{~m}$ (full scale) for the LiDAR profile $1 \mathrm{set}, 0.68 \mathrm{~m} / \mathrm{s}$ and $0.001 \mathrm{~m}$ (full scale) for the LiDAR profile 2 set, and the von Kármán constant is equal to 0.41 .

It should be noted that while many literature sources advocate the high accuracy of LiDAR measurements in terms of 10-min mean wind speed profiles (e.g. Wilczak et al., 1996; Smith et al., 2006; Pena et al., 2009), some issues still remain concerning the reliability of turbulence measurements, which are usually considered underestimated due to the spatial filtering performed by the LiDAR instrument to obtain the wind measurements (Wilczak et al., 1996; Sathe et al., 2011; Sathe and Mann, 2013). In that regard, turbulent kinetic energy profiles imposed at the inlet of the computational domain can be considered slightly underestimated with respect to the real ones.

The other boundary conditions, shown in Fig. 13, were defined in order to reproduce the WT conditions as closely as possible. At the bottom, sides and top of the computational domain and on the surfaces of the obstacles (e.g. buildings and bridges) standard wall functions by Launder and Spalding (1974) with roughness modification by Cebeci and Bradshaw (1977) were used. Equivalent sand-grain roughness height $\left(k_{s}\right)$ values consistent with the surface roughness of the WT walls (side and top walls) and the materials employed to build the urban district model were used according to the experimental values given by Hiziroglu and Kosonkorn (2006). In particular a value of $k_{s}$ equal to 4.0 $\times 10^{-6} \mathrm{~m}$ was employed to reproduce the medium-density fibreboard and closed-cell PVC foamboard roughness, such as for the buildings, bridges, ground surface of the urban model and bottom of the WT. A value of $k_{s}$ equal to $1.0 \times 10^{-6} \mathrm{~m}$ was used to reproduce the roughness of the steel and glass of the sides and top of the WT. In order to use the open-source CFD code OpenFOAM 2.3.0, the so-termed epsilonWallFunction, kqRWallFunction, nutkRoughWallFunction and nutkWallFunction (OpenFOAM 2.3.0) were used to solve the turbulence dissipation rate $(\varepsilon)$, the turbulent kinetic energy $(k)$, the turbulence viscosity $(\nu)$ both for the rough and slip wall conditions, respectively. Finally, zero static gauge pressure was imposed at the outlet face (Fig. 13).
In view of analyzing the flow through the upstream part of the computational domain (Blocken et al., 2007a), the horizontal homogeneity of the mean wind velocity profiles between the inlet face and the position of the first building of the urban model was also investigated for all the three CFD cases in an empty domain with the same dimensions of the one including the urban district. The evolution of the mean velocity profiles (i.e. WT profile, LiDAR profile 1 and LiDAR profile 2) was monitored along a vertical $\mathrm{H}-\mathrm{L}$ plane in the center of the domain (see Fig. 13): for all the cases, at the height $0.033 \mathrm{z} / \mathrm{H}$, which is the first measuring height above the bottom, the mean wind velocity at the position of the first building increases less than $1 \%$ with respect to the corresponding inflow values.

\subsection{Solver settings}

The CFD simulations were performed using the 3D steady-state RANS approach and the realizable $k-\varepsilon$ turbulence model (Shih et al., 1995). Recent review studies have shown that RANS simulations are still most often used in the fields of building simulation and wind engineering (e.g. Blocken, 2014, 2018). Second-order discretization schemes "linearLimited" were used for the convective and viscous terms of the governing equations (OpenFOAM 2.3.0). The SIMPLE algorithm was adopted to couple pressure and velocity fields (Patankar, 1980). Iterative convergence of each simulation was considered to be achieved when the residuals showed no further discernible fluctuations during the iterative process: $10^{-8}$ for the mean velocity components, $10^{-7}$ for the turbulent kinetic energy and turbulence dissipation rate, and $10^{-6}$ for the continuity. All simulations were performed on a High Performance Computing (HPC) system at Department of Civil, Chemical and Environmental Engineering (Dipartimento di Ingegneria Civile, Chimica ed Ambientale - DICCA) using 64 cores in parallel, with $256 \mathrm{~GB}$ of RAM at $1.4 \mathrm{GHz}$.

\section{Comparison between WT and CFD simulations}

\subsection{Contours of wind speed ratio}

In order to investigate the performance of the three CFD cases (i.e. WT profile case, LiDAR profile 1 case and LiDAR profile 2 case) in predicting the wind-flow pattern throughout the UBL, contours of the mean wind speed ratio were analyzed in horizontal sections at three different levels $(0.02 \mathrm{~m}, 0.07 \mathrm{~m}$ and $0.20 \mathrm{~m}$, corresponding to $6 \mathrm{~m}, 21 \mathrm{~m}$ 
and $60 \mathrm{~m}$ above sea level and $2 \mathrm{~m}, 17 \mathrm{~m}$ and $56 \mathrm{~m}$ above the ground surface), and one vertical section made along the central plane passing through the line L2-L2' (see Fig. 13) of the computational domain. This line is aligned with the line $\mathrm{L}$ (see Fig. 10a) along which the measuring positions $\mathrm{L} 2{ }_{1}-\mathrm{L} 2{ }_{5}$ were chosen. The three levels $(0.02 \mathrm{~m}, 0.07 \mathrm{~m}$ and $0.20 \mathrm{~m}$ ) were chosen in order to analyze the wind-flow pattern at pedestrian level (at $z=0.02 \mathrm{~m}$, i.e. $2 \mathrm{~m}$ at full scale), inside the UCL (at $z$ $=0.07 \mathrm{~m}$, i.e. $17 \mathrm{~m}$ at full scale) and inside the upper part of the roughness sub-layer (RS) over the buildings (at $z=0.20 \mathrm{~m}$, i.e. $56 \mathrm{~m}$ at full scale) (Barlow, 2014; Ricci et al., 2017a). The wind speed ratio is defined as the local wind speed $(U)$ divided by the inflow wind speed measured at $0.6 \mathrm{~m}$ (i.e. $180 \mathrm{~m}$ at full scale) above the bottom (i.e. the sea level at full scale), $U_{i n, 0.6 m}$, which corresponds to the highest measurement position in the WT.

Along the central plane L2-L2' (Fig. 14a, b, c), different UBL developments are found for the three CFD cases analyzed. The WT profile case showed less vertical wind profile development above the UCL compared to the other two cases, which is probably due to the higher roughness length of its inlet mean speed profile compared to the ones of LiDAR profile 1 case and LiDAR profile 2 case. The LiDAR profile 2 case, in particular, showed a strong effect of the increasing surface drag as the urban canopy is approached (Fig. 14c, f, i, l).

At level $z=0.02 \mathrm{~m}$ above the bottom (Fig. 14d, e, f), the LiDAR profile 2 case showed higher normalized wind speed values compared to WT profile and LiDAR profile 1 cases as expected because of its lower roughness length. However, since the ancient fortress (called "Fortezza Antica") of Livorno and the bridge of "Viale della Cinta Esterna" (indicated in the figures by "F" and "bridge" respectively) obstruct the wind-flow funneling along Canale Rosciano and Piazza Luogo Pio (indicated in the figures by "CR" and "LP" respectively), the three CFD cases showed approximately the same wind-flow pattern inside the sheltered part of the district.

At level $z=0.07 \mathrm{~m}$ above the bottom (Fig. 14g, h, i), LiDAR profile 1 and 2 cases showed higher wind speed ratios compared to the WT profile case in the upstream regions of the urban model. The wind speed ratios in the UCL, however, are comparable for all the three cases.

At level $z=0.20 \mathrm{~m}$ above the bottom (Fig. $14 \mathrm{j}, \mathrm{k}, \mathrm{l}$ ), the wind-flow pattern became more homogeneous as the local drag due to the urban canopy decreases.

\subsection{Vertical wind profiles}

In order to understand how sensitive the wind speed values are due to the different inflow conditions (i.e. WT profile, LiDAR profile 1 and LiDAR profile 2) imposed at the inlet face, the wind speed profiles of the three CFD cases were analyzed along three lines (L1, L2 and L3) at 15 measuring positions ( $\mathrm{L}_{1-5}, \mathrm{~L}_{1-5}$ and $\left.\mathrm{L}_{1-5}\right)$ and compared with the WT data (Fig. 15). In the abscissae, the ratio $U / U_{\text {ref }}$ is reported, where $U$ indicates the wind speed value at different heights and $U_{\text {ref }}$ is the maximum local wind speed of each CFD case at $z_{\text {ref }}=0.6 \mathrm{~m}$. Here, the ordinates are normalized by $z_{\text {ref }}=0.6 \mathrm{~m}$, which corresponds to the highest measurement position in the WT section.

In general, Fig. 15 shows that the wind speed profiles at the lower heights, i.e. below $0.1 z / z_{\text {ref, }}$ converge towards similar values at most of the measuring positions because of the influence of the local-scale forcing effects due to the geometry of the urban district. In contrast, in the higher part the wind speed profiles of the three CFD cases preserve almost the same difference (in terms of magnitude) with respect to the

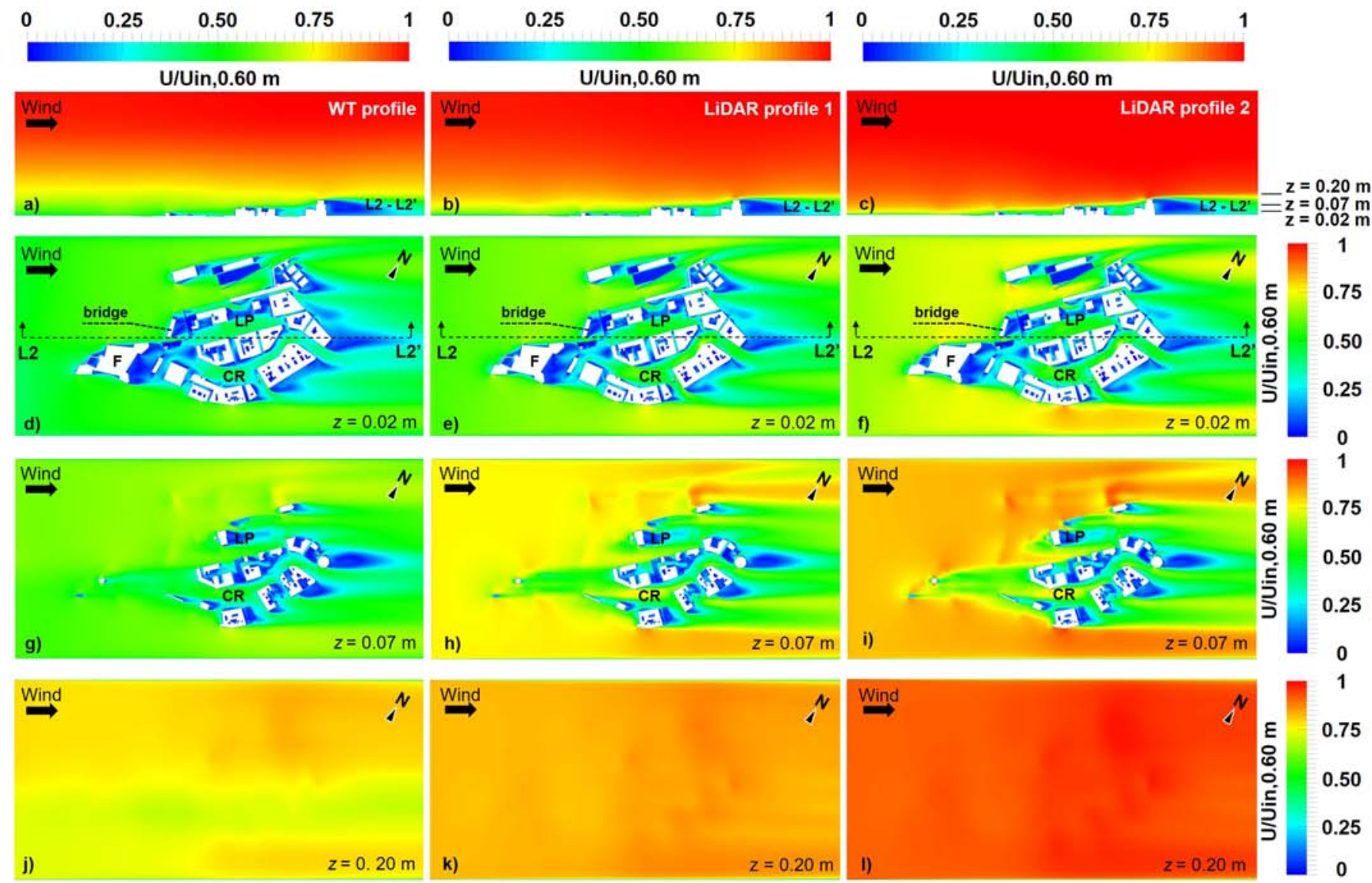

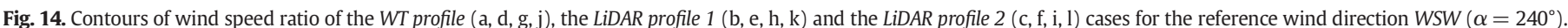

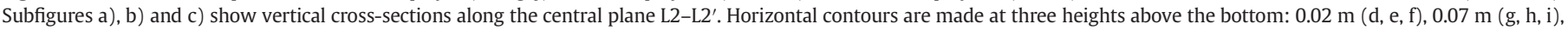

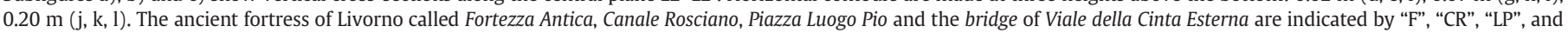
"bridge" in the figures, respectively. 

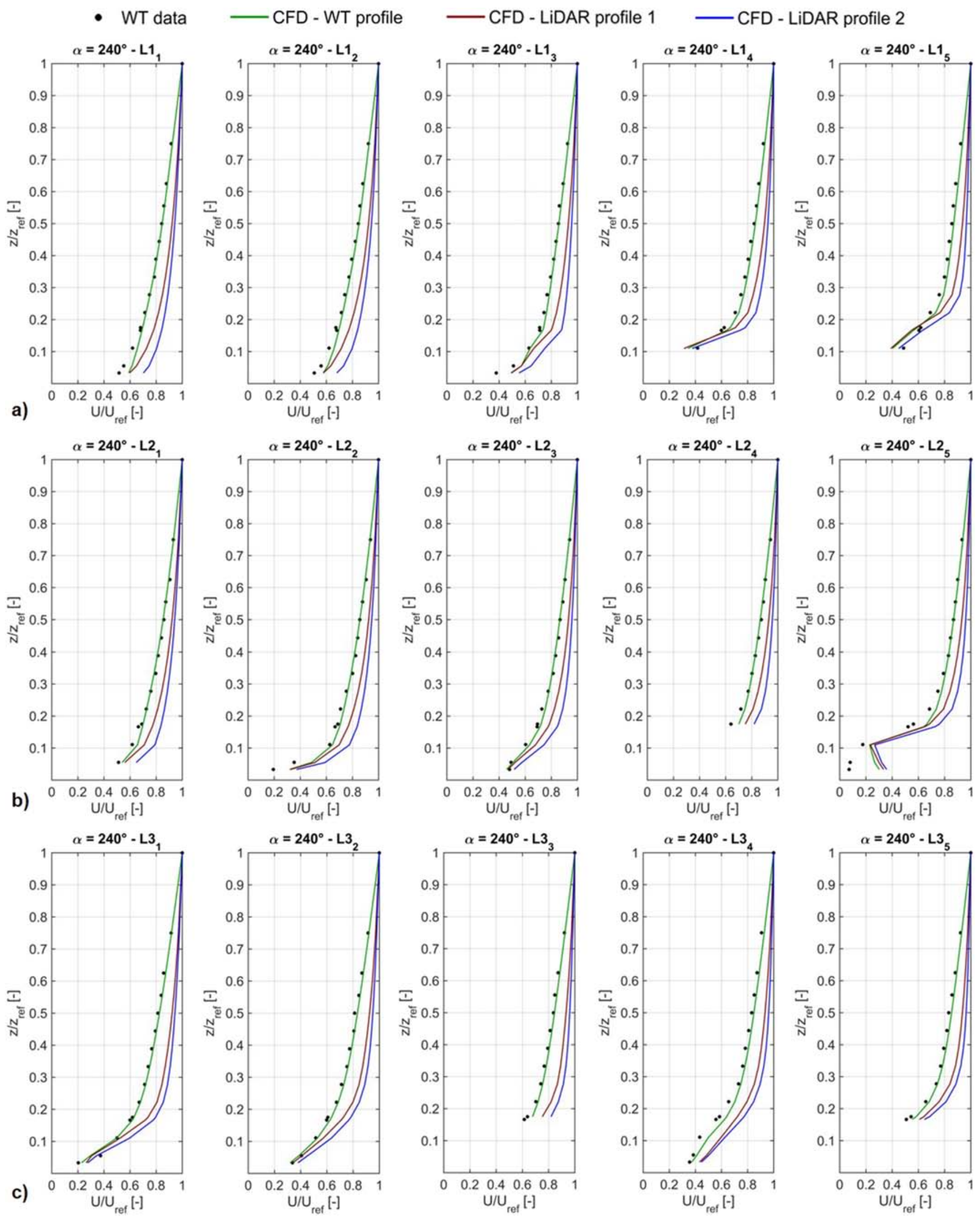

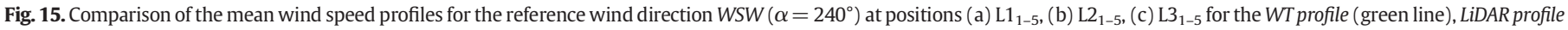

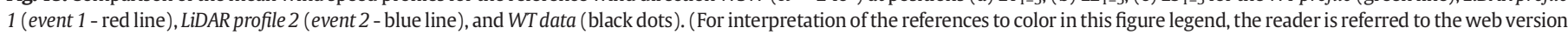
of this article.) 
WT data, as they have at the inlet (Fig. 15a). The WT profile case, for which the approach-flow profiles of the WT tests were used as inflow conditions (see Section 5.2) for the CFD simulations, shows a better agreement with WT data compared to the LiDAR profile cases at all measuring positions L and for the entire height of the ABL (Fig. 15). A quantitative estimation of the deviations between three CFD cases and WT data is provided in the Section 7.

At the positions $\mathrm{L} 1_{1}$ and $\mathrm{L} 1_{2}$ (Fig. 15a), which are not completely sheltered by obstacles (see Fig. 10a), the wind speed profiles for the three CFD cases are found to be mostly influenced by the roughness height imposed at the bottom surface by the wall functions. In contrast, the profiles measured at position $\mathrm{L}_{3}$ (Fig. 15a), placed nearby buildings (see Fig. 10a), are clearly affected by the presence of the obstacles in the lower part, between 0 and about $0.2 z / z_{\text {ref. }}$. At the positions $\mathrm{L}_{4}$ and $\mathrm{L} 1_{5}$ (Fig. 15a), the profiles are found to be strongly affected by the obstacles both at smaller and larger heights and the wind speed profiles of WT profile, LiDAR profile 1 and 2 cases are almost perfectly coincident at the lowest heights.

At positions $\mathrm{L} 2_{1}, \mathrm{~L} 2_{2}$, and $\mathrm{L} 2_{3}$ (Fig. 15b), the profiles of the WT profile and LiDAR profile 1 cases, upstream (at $\mathrm{L} 2_{1}$ ) and downstream (at $\mathrm{L} 2_{2}$ and $\mathrm{L}_{3}$ ) of the bridge of Viale della Cinta Esterna, are clearly affected by the obstacles and almost coincident between about 0.033 and $0.05 z / z_{\text {ref. }}$. Conversely, the LiDAR profile 2 case shows larger wind speed values compared to the other CFD cases at the same positions. At position $\mathrm{L}_{4}$ (Fig. 15b), the profiles show large discrepancies near the roof of the underlying building. At position L2 5 (Fig. 15b), since this position is placed in the middle of the curve of Canale Rosciano and in the leeward zone of surrounding buildings, the profiles show a strong decrease of wind speed values due to the canyoning effect (Ricci et al., 2017a, 2017b).

Along the line L3 (see Fig. 10a), since Canale Rosciano is almost aligned with the approach-flow direction, the wind flow funnels over the canal and the wind speed increases from $\mathrm{L}_{3}$ to $\mathrm{L}_{4}$ (except for $\mathrm{L}_{3}$ which is blocked by the urban model between 0 and $0.17 \mathrm{z} / z_{\text {ref }}$ ) mostly in the lower part, possibly due to canyoning effects (Fig. 15c). Finally, the profiles at position $\mathrm{L}_{5}$ show a similar trend to the profiles measured at position $\mathrm{L}_{3}$ (Fig. 15c).

\section{Deviations caused by the inflow conditions}

In order to quantify the deviations in terms of mean wind speed, caused by different sets of inflow profiles (i.e. the WT profile set, LIDAR profile 1 set and LiDAR profile 2 set) each one representative of a neutral atmospheric stability condition, two validation metrics were used (Chang and Hanna, 2004), the fractional bias (FB) and the correlation coefficient $(R)$. The validation metrics were calculated as follow:

$$
F B=2 \frac{(\bar{O}-\bar{P})}{(\bar{O}+\bar{P})}
$$

$R=2 \frac{\overline{(O-\bar{O})} \cdot \overline{(P-\bar{P})}}{\left(\sigma_{O} \cdot \sigma_{P}\right)}$

where $P$ and $O$ are the predicted (CFD) and the observed (WT) values, and $\sigma_{P}$ and $\sigma_{O}$ are the standard deviations over a specific dataset. The statistical performance of the CFD cases were evaluated at all measuring positions (A and $\mathrm{L}$ ) and three specific levels $(0.02 \mathrm{~m}, 0.07 \mathrm{~m}$ and $0.20 \mathrm{~m})$ above the bottom. The following criterion was adopted: firstly, the simulated data of the WT profile case were compared with the measured WT data in order to validate the numerical results, afterwards, the simulated LiDAR profile 1 and 2 data were compared with the (validated) simulated WT profile data in order to quantitatively evaluate the deviations that occur when adopting different sets of inflow conditions in terms of $U, k$ and $\varepsilon$.
The comparison between the simulated WT profile data and the measured WT data is reported in the first column of Table 2 and graphically displayed in Fig. 16. On the abscissa the mean wind speed values $\left(U_{W T}\right)$ of the WT data are normalized with the corresponding reference wind speed value at $z_{\text {ref }}=0.6 \mathrm{~m}\left(U_{\text {ref }}\right)$. On the ordinate the equivalent ratios $U_{C F D} / U_{\text {ref }}$ of the WT profile data are reported.

At the level $z=0.02 \mathrm{~m}$ (Table 2 and Fig. 16a), the $F B$ values indicate an overestimation $(-0.10)$ of the WT profile data with respect to the measured WT data and a quite symmetric distribution around the diagonal (except for three samples), respectively. A limited deviation from the WT profile data is also indicated by the correlation coefficient $(R)$ value, equal to 0.77 , which marks a satisfactory agreement with $W T$ data. Note that this value is mainly affected by two points, corresponding to positions $\mathrm{L} 2_{2}$ and $\mathrm{L} 2_{5}$, where the values are strongly overestimated by the numerical model. This is probably due to the fact that their position is very close to walls that sheltered the multi-hole probe sensor during the WT tests rather than to errors or uncertainties in the numerical simulation (see Fig. 10a). At the levels $z=0.07 \mathrm{~m}$ and $z$ $=0.20 \mathrm{~m}$, the above mentioned overestimation gradually decreases with respect to the lower level as these measurement positions are gradually less affected by the buildings of the urban model. That is the reason why the correlation $(R)$ with the $W T$ data becomes closer to 1 (i.e. 0.95 at $z=0.07 \mathrm{~m}$ and 0.98 at $z=0.20 \mathrm{~m}$ ).

The comparison between the cases LiDAR profile 1 and 2 and the case WT profile is reported in the third and fourth column of Table 2, respectively, and graphically displayed in Fig. 17. The FB values are almost constant at each level analyzed $(z=0.02,0.07$ and $0.20 \mathrm{~m})$, showing an overestimation of the data of both LiDAR profile cases with respect to the WT profile data. A satisfactory correlation $(R)$ between both sets of data of LiDAR profile cases and WT profile data is found at both levels 0.02 and $0.07 \mathrm{~m}: 0.95$ and 0.97 for the LiDAR profile 1 case, and 0.98 and 0.99 for the LiDAR profile 2 case, respectively. Conversely, at the level $z=0.20 \mathrm{~m}$, the correlation of both LiDAR profile 1 and 2 cases drops to 0.17 and 0.51 , respectively. This is due to the fact that in the RS the wind flow is influenced by the average effect of the urban obstacles beneath so that the wind speed values of both LiDAR profile cases of Fig. 17c converge towards very similar values (also to the respective inlet values) plus or minus small random fluctuations. This randomness causes the correlation coefficient to decrease that much with respect to the lower levels $(z=0.02 \mathrm{~m}$ and $z=0.07 \mathrm{~m})$. This is clearly visible in Fig. 17c from the different pendency assumed by the clouds of samples (blue and red dashed lines) with respect to the reference diagonal.

\section{Table 2}

Validation metrics for the mean wind speed $U$ for the three CFD cases (WT profile, LiDAR profile 1 and LiDAR profile 2) at all 25 measurement positions (A and L), for the reference wind direction WSW $\left(\alpha=240^{\circ}\right)$ and three levels above the bottom: $0.02 \mathrm{~m}, 0.07 \mathrm{~m}$ and $0.20 \mathrm{~m} . F B=$ Fractional Bias and $R=$ correlation coefficient. The ideal values are respectively equal to 0 for $F B$ and 1 for $R$. The number of measurement positions (samples) considered at the different levels is also indicated: samples less than $25(\mathrm{~A}+\mathrm{L})$ occur when the $\mathrm{L}$ measured profiles lie on top of buildings and bridges.

\begin{tabular}{llll}
\hline $\begin{array}{l}z=0.02 \\
\mathrm{~m}\end{array}$ & $\begin{array}{l}\text { WT profile vs WT } \\
\text { data }\end{array}$ & $\begin{array}{l}\text { LiDAR profile 1 vs WT } \\
\text { profile }\end{array}$ & $\begin{array}{l}\text { LiDAR profile 2 vs WT } \\
\text { profile }\end{array}$ \\
\hline FB & -0.10 & -0.10 & -0.17 \\
$R$ & 0.77 & 0.95 & 0.98 \\
Samples & $18 / 25$ & $18 / 25$ & $18 / 25$ \\
& & LiDAR profile 1 vs $W T$ & LiDAR profile 2 vs $W T$ \\
$z=0.07$ & WT profile vs $W T$ & profile & profile \\
$\mathrm{m}$ & data & -0.09 & -0.18 \\
\hline FB & -0.06 & 0.97 & 0.99 \\
$R$ & 0.82 & $20 / 25$ & $20 / 25$ \\
Samples & $20 / 25$ & & \\
& & LiDAR profile 1 vs $W T$ & LiDAR profile 2 vs $W T$ \\
$z=0.20$ & $W T$ profile vs $W T$ & profile & profile \\
m & data & -0.11 & -0.16 \\
\hline FB & -0.02 & 0.17 & 0.51 \\
$R$ & 0.93 & $25 / 25$ & $25 / 25$ \\
Samples & $25 / 25$ & & \\
\hline
\end{tabular}



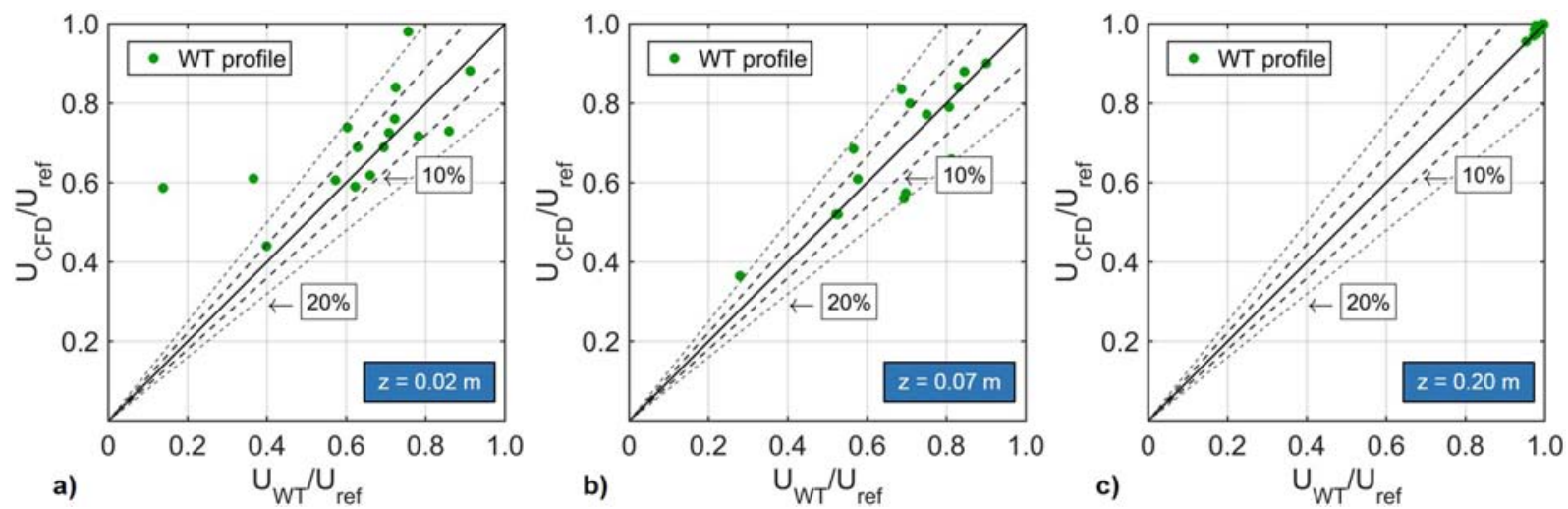

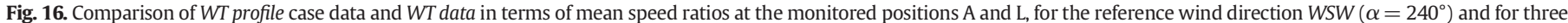
heights: (a) $0.02 \mathrm{~m},(b) 0.07 \mathrm{~m}$ and (c) $0.20 \mathrm{~m}$. Dashed black lines correspond to $10 \%$ and $20 \%$ error bands, as indicated.

\section{Discussion and conclusions}

In the present study, the impact of three different sets of inflow conditions (i.e. WT profile, LIDAR profile 1 and LiDAR profile 2), each one representative of a specific neutral atmospheric stability condition, was investigated by means of CFD simulations performed on an urban case study. A district of Livorno City (Italy), called Quartiere La Venezia, was chosen as test case and 3D steady RANS simulations were performed on a reduced-scale model geometry (1:300) for winds blowing from the Tyrrhenian Sea $\left(W S W, \alpha=240^{\circ}\right)$. The first set of profiles $(U, k$ and $\varepsilon)$, termed WT profile, were defined on the basis of mean wind speed $(U)$ and wind speed standard deviations $\sigma_{u}(z), \sigma_{v}(z), \sigma_{w}(z)$ values along three lines (L1-L1', L2-L2', L3-L3') measured approximately $1 \mathrm{~m}$ upstream of the urban model in the WT test section. The second and the third sets of profiles ( $U, k$ and $\varepsilon$ ), termed LiDAR profile 1 and 2 were defined on the basis of mean wind speed and turbulence values measured by the LiDAR wind profiler installed in the Port of Livorno during two selected meteorological events, so-called event 1 and 2 respectively, corresponding to Libeccio wind conditions. CFD results (in terms of wind speed) of the WT profile case were firstly compared and then validated with respect to the WT data (see also Ricci et al., 2017b, 2018). Afterwards, the LiDAR profile 1 and 2 data were compared, in terms of wind speed, with the (validated) WT profile data in order to evaluate quantitatively the deviations that occur when using more realistic inlet profiles (in terms of $U, k$ and $\varepsilon$ ) in 3D steady RANS simulations on the same reduced-scale urban model. Several limitations for the current stage of this research project should be noted:

- Although the simulated urban district may be considered representative of a wide range of typologies of historical Italian cities and most of the outcomes can be considered of general applicability, specific studies are required when a detailed description of the urban flow field in a city is needed.

- In absence of more suitable instrumentation able to properly catch the wind-flow pattern also in reversal and separation zones, a multihole pressure probe (i.e. the Cobra probe) was used to measure the wind velocity at all positions (A and L) during the WT tests. This instrument is able to measure within an angle of acquisition of $\pm 45^{\circ}$ with respect to the incoming flow, which may be not sufficient to ensure the accuracy of measurements at the two positions $\mathrm{L}_{2}$ and $\mathrm{L} 2_{5}$ (Fig. 16a), where the wind flow clearly exhibits a sheltering effects caused by the upwind building walls. However, due to the good alignment between the Canale Rosciano and the approach-flow profiles $\left(\alpha=240^{\circ}\right)$, only the WT data belonging to level $z=0.02 \mathrm{~m}$ of positions $\mathrm{L} 22_{2}$ and $\mathrm{L} 2{ }_{5}$ were found to be not fully reliable.

- LiDAR wind profilers provide turbulence measurements which are expected to be slightly underestimated.

- The sets LiDAR profile 1 and LiDAR profile 2 were not experimentally simulated in the WT whereas the WT profile set was extensively analyzed using both experimental and numerical techniques.

- The approximated geometrical model simulated by CFD showed some differences with respect to the physical model constructed for WT testing. In the computational domain, the pitched roofs of the buildings were replaced by flat roofs and constructed using only hexahedral and prismatic control volumes to maximize the numerical accuracy and avoid possible converge problems often caused by tetrahedral grids when combined with the required second-order discretization schemes.
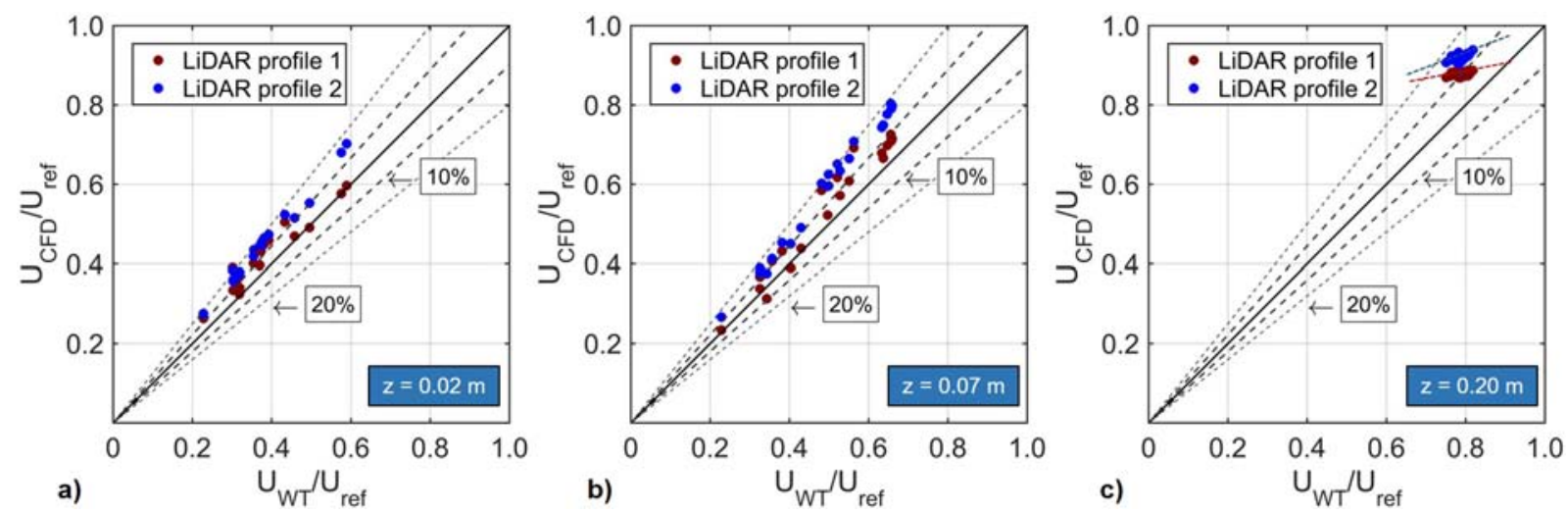

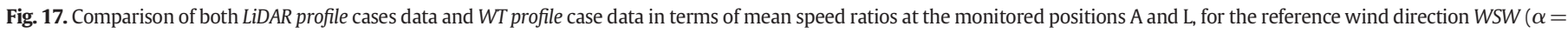

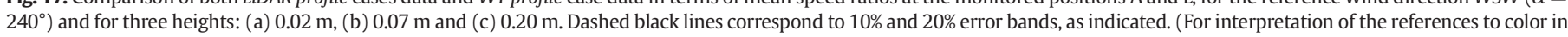
this figure, the reader is referred to the web version of this article.) 
- All the simulations were performed using the 3D steady RANS approach which is known to have some limitations in predicting separation and reversal flow zones. However, the use of a more sophisticated numerical approach, as the large-eddy simulation (LES), requires a higher complexity of the computational grid which makes therefore the CFD simulations computational much more demanding (Blocken, 2018).

In spite of these limitations, the study was successful in deriving a number of conclusions, the most important of which being that the choice of different mean wind speed profiles representative of several neutral atmospheric stability conditions when performing CFD and WT tests, affects the wind flows mainly above the UCL and RS while this is much less pronounced within the UCL. In particular:

- The vertical contours of the wind speed ratio showed different UBL developments for the three CFD cases analyzed. The set of inflow conditions with the smallest aerodynamic roughness length value and the highest mean wind speed values, i.e. the LiDAR profile 2 , showed a stronger effect of the increasing drag on the wind flow as the urban canopy was approached.

- The horizontal contours made inside the UCL and RS showed some differences in terms of wind-flow pattern, among the three CFD cases, mostly upstream and downstream the urban district. In contrast, the three CFD cases showed a very similar wind-flow pattern inside the urban district as also found by the authors in the previous publication Ricci et al. (2018).

- The wind speed profiles as well the correlation coefficient $(R)$ highlighted two different behaviors of the wind flow throughout the computational domain. The first occurs at the lowest levels or in general inside the UCL, where the wind speed values (of the three CFD cases) measured near the ground level were found to converge towards very similar values at those positions (i.e. $\mathrm{L} 1_{4}, \mathrm{~L} 1_{5}, \mathrm{~L} 2_{2}, \mathrm{~L} 2_{3}$, $\mathrm{L} 2_{5}, \mathrm{~L} 3_{1}, \mathrm{~L} 3_{2}, \mathrm{~L} 3_{4}, \mathrm{~L} 3_{5}$ ) taken in the proximity of buildings, bridges or any other obstacle. This is also confirmed by the correlation found between the LiDAR profile 1 and 2 data with respect to the WT profile data, $95 \%$ and $98 \%$ respectively (at $z=0.02 \mathrm{~m}$ above the bottom). The second occurs at the highest levels, where the mean wind speed profiles of the LiDAR profiles 1 and 2 cases showed considerable differences in terms of magnitude with respect to the benchmark (i.e. WT profile). These results were clearly confirmed once again by the low correlation coefficients found between the LiDAR profiles 1 and 2 data with respect to the $W T$ profile data, $17 \%$ and $51 \%$ respectively.

Overall, the relevance of this conclusion depends on the specific application that one is interested in and which part of the boundary layer is under investigation. As found by the authors in the previous publication Ricci et al. (2018), for applications dealing with wind flow predictions inside the UCL and in particular nearby the ground surface (e.g. for pedestrian-level wind comfort and/or air pollution), the use of different inflow mean wind speed profiles (representative of different neutral atmospheric conditions) might not be very relevant in such places where the obstacles strongly affect the flow, so much that wind speed profiles here tend to converge towards similar values at levels ranging between 0 and $1.5 h_{b}$ (where $h_{b}$ is the maximum building height equal to $0.15 \mathrm{~m}$ ). For applications dealing with the wind flow modeling above the UCL at higher layers within the RS, e.g. wind loads on high-rise building facades, the use of different inflow mean wind speed profiles is definitely not negligible as the results of CFD simulations and WT tests can be strongly affected by the different wind speed profiles there.

\section{Acknowledgements}

The authors gratefully acknowledge the Port Authority of Livorno for the use of data obtained by its anemometric monitoring network. All the monitoring devices and the HPC system at DICCA were funded by the European Cross-border Programme Italy/France "Maritime" 2007-2013 through the "Wind and Ports" (CUP: B87E09000000007) and "Wind, Ports, and Sea" (CUP: B82F13000100005) projects.

This research has been carried out in the framework of the Project "Wind monitoring, simulation and forecasting for the smart management and safety of port, urban and territorial systems", funded by Compagnia di San Paolo (grant number 2015.0333, ID ROL: 9820) in the period 2016-2018.

\section{References}

An, K., Fung, J.C.H., Yim, S.H.L., 2013. Sensitivity of inflow boundary conditions on downstream wind and turbulence profiles through building obstacles using a CFD approach. J. Wind Eng. Ind. Aerodyn. 115, 137-149.

Antoniou, N., Montazeri, H., Wigo, H., Neophytou, M., Blocken, B., Sandberg, M., 2017. CFD and wind tunnel analysis of outdoor ventilation in a real compact heterogeneous urban area: evaluation using "air delay". Build. Environ. 126, 355-372.

Armitt, J., Counihan, J., 1968. The simulation of the atmospheric boundary layer in a wind tunnel. Atmos. Environ. 2, 49-71.

Balendra, T., Shah, D.A., Tey, K.L., Kong, S.K., 2002. Evaluation of flow characteristics in the NUS-HDB Wind Tunnel. J. Wind Eng. Ind. Aerodyn. 90, 675-688.

Barlow, J.F., 2014. Progress in observing and modelling the urban boundary layer. Urban Climate 10, 216-240.

Barlow, T., Rae Jr., W.H., Pope, A., 1999. Low-speed Wind Tunnel Testing. John Wiley \& Sons, Inc.

Blocken, B., 2014. 50 years of computational wind engineering: past, present and future. J. Wind Eng. Ind. Aerodyn. 129, 69-102.

Blocken, B., 2015. Computational Fluid Dynamics for Urban Physics: importance, scales, possibilities, limitations and ten tip and tricks towards accurate and reliable simulations. Build. Environ. 91, 219-245.

Blocken, B., 2018. LES over RANS in building simulation for outdoor and indoor applications: a foregone conclusion. Build. Simul. 11, 821-870.

Blocken, B., Stathopoulos, T., Carmeliet, J., 2007a. CFD simulation of the atmospheric boundary layer: wall function problems. Atmos. Environ. 41, 238-252.

Blocken, B., Carmeliet, J., Stathopoulos, T., 2007b. CFD evaluation of the wind speed conditions in passages between buildings - effect of wall-function roughness modifications on the atmospheric boundary layer flow. J. Wind Eng. Ind. Aerodyn. 95, 941-962.

Blocken, B., Janssen, W.D., van Hooff, T., 2012. CFD simulation for pedestrian wind comfort and wind safety in urban areas: general decision framework and case study for the Eindhoven University campus. Environ. Model Softw. 30, 15-34.

Blocken, B., van der Hout, A., Dekker, J., Weiler, O., 2015. CFD simulation of wind flow over natural complex terrain: case study with validation by field measurements for Ria de Ferrol, Galicia, Spain. J. Wind Eng. Ind. Aerodyn. 147, 43-57.

Blocken, B., Vervoort, R., van Hooff, T., 2016. Reduction of outdoor particulate matter concentrations by local removal in semi-enclosed parking garages: a preliminary case study for Eindhoven city center. J. Wind Eng. Ind. Aerodyn. 159, 80-98.

Bossard, M., Feranec, J., Otahel, J., 2000. Corine land cover technical guide - addendum 2000, EEA Technical Report No. 40, Copenhagen

Buccolieri, R., Gromke, C., Di Sabatino, S., Ruck, B., 2009. Aerodynamic effects of trees on pollutant concentration in street canyons. Sci. Total Environ. 407, 5247-5256.

Burlando, M., Pizzo, M., Repetto, M.P., Solari, G., De Gaetano, P., Tizzi, M., 2014. Short-term wind forecast for the safety management of complex areas during hazardous wind events. J. Wind Eng. Ind. Aerodyn. 135, 170-181.

Burlando, M., Tizzi, M., Solari, G., 2017. Characteristics of downslope winds in the Liguria Region. Wind Struct. 24, 613-635.

Carpentieri, M., Robins, A.G., 2015. Influence of urban morphology on air flow over building arrays. J. Wind Eng. Ind. Aerodyn. 145, 61-74.

Carpentieri, M., Hayden, P., Robins, A.G., 2012. Wind tunnel measurements of pollutant turbulent fluxes in urban intersections. Atmos. Environ. 46, 669-674.

Cebeci, T., Bradshaw, P., 1977. Momentum Transfer in Boundary Layers. Hemisphere Publishing Corporation, New York.

Cermak, J.E., 1972. Applications of fluid mechanics to wind engineering - a Freeman Scholar lecture. Transactions of the American Society of Mechanical Engineers. Journal of Fluids Engineering 1, 97, 9-38.

Chang, J.C., Hanna, S.R., 2004. Air quality model performance evaluation. Meteorog. Atmos. Phys. 87, 167-196.

Cheng, W.C., Porté-Agel, F., 2015. Adjustment of turbulent boundary-layer flow to idealized urban surfaces: a large-eddy simulation study. Bound.-Layer Meteorol. 129, $1-23$.

Coceal, O., Belcher, S.E., 2004. A canopy model of mean winds through urban areas. Q. J. R. Meteorol. Soc. 130, 1349-1372.

Counihan, J., 1969. An improved method of simulating an atmospheric boundary layer in a wind tunnel. Atmos. Environ. 3, 197-214.

Counihan, J., 1970. Further measurements in a simulated atmospheric boundary layer. Atmos. Environ. 4, 259-275.

Emeis, S., Harris, M., Banta, R.M., 2007. Boundary-layer anemometry by optical remote sensing for wind energy applications. Meteorol. Z. 16, 337-347.

Farell, C., Iyengar, A.K.S., 1999. Experiments on the wind tunnel simulation of atmospheric boundary layer. J. Wind Eng. Ind. Aerodyn. 79, 11-35.

Fox, R.W., McDonald, A.T., Pritchard, P.J., 1998. Introduction to Fluid Mechanics. second ed. John Wiley \& Sons, New York. 
Franke, J., Hellsten, A., Schlünzen, H., Carissimo, B., 2007. Quality assurance and improvement of microscale meteorological models. COST Action 732.

Fujii, T., Fukuchi, T., 2005. Laser Remote Sensing. CRC Press.

García Sánchez, C., Philips, D.A., Gorlé, C., 2014. Quantifying inflow uncertainties for CFD simulations of the flow in downtown Oklahoma City. Build. Environ. 78, 118-129.

García Sánchez, C., van Beeck, J., Gorlé, C., 2018. Predictive large eddy simulations for urban flows: challenges and opportunities. Build. Environ. 139, 146-156.

Gromke, C., Buccolieri, R., Di Sabatino, S., Rucka, B., 2008. Dispersion study in a street canyon with tree planting by means of wind tunnel and numerical investigations - evaluation of CFD data with experimental data. Atmos. Environ. 42, 8640-8650.

Hertwig, D., Efthimiou, G.C., Bartzis, J.G., Leitl, B., 2012. CFD-RANS model validation of turbulent flow in a semi-idealized urban canopy. J. Wind Eng. Ind. Aerodyn. 111, 61-72.

Hiziroglu, S., Kosonkorn, P., 2006. Evaluation of surface roughness of Thai medium density fiberboard (MDF). Build. Environ. 41, 527-533.

Hornikx, M., Dohmen, M., Conen, K., van Hooff, T., Blocken, B., 2018. The wind effect on sound propagation over urban areas: predictions for generic urban sections. Build. Environ. 144, 519-531.

IEA, 2013. Ground-based vertically-profiling remote sensing for wind resource assessment, A. Clifton, D. Elliott, M. Courtney (Eds.), Technical Report IEA Wind RP 15. International Energy Agency.

Iousef, S., Montazeri, H., Blocken, B., van Wesemael, P.J.V., 2017. On the use of nonconformal grids for economic LES of wind flow and convective heat transfer for a wall-mounted cube. Build. Environ. 119, 44-61.

Irwin, H.P.A.H., 1980. The design of spires for wind simulation. J. Wind Eng. Ind. Aerodyn. 7, 361-366.

Janssen, W.D., Blocken, B., van Hooff, T., 2013. Pedestrian wind comfort around buildings: comparison of wind comfort criteria based on whole-flow field data for a complex case study. Build. Environ. 59, 547-562.

Jeanjean, A.P.R., Hinchliffe, G., McMullan, W.A., Monks, P.S., Leigh, R.J., 2015. A CFD study on the effectiveness of trees to disperse road traffic emissions at a city scale. Atmos. Environ. 120, 1-14.

Kastner-Klein, P., Rotach, M.W., 2004. Mean flow and turbulence characteristics in an urban roughness sublayer. Bound.-Layer Meteorol. 111, 55-84.

Kondo, H., Asahi, K., Tomizuka, T., Suzuki, M., 2006. Numerical analysis of diffusion around a suspended expressway by a multi-scale CFD model. Atmos. Environ. 40, 2852-2859.

Kozmar, H., 2010. Scale effect in wind tunnel modeling of an urban atmospheric boundary layer. Theor. Appl. Climatol. 100, 153-162.

Kozmar, H., 2011. Truncated vortex generators for part-depth wind-tunnel simulations of the atmospheric boundary layer flow. J. Wind Eng. Ind. Aerodyn. 99, 130-136.

Launder, B.E., Spalding, D.B., 1974. The numerical computation of turbulent flows. Comput. Methods Appl. Mech. Eng. 3, 269-289.

Lloyd, A., 1967. The generation of shear flow in a wind tunnel. Q. J. R. Meteorol. Soc. 93. 79-96.

Meroney, R.N., 2016. Ten questions concerning hybrid computational/physical model simulation of wind flow in the built environment. Build. Environ. 96, 12-21.

Mochida, A., Iizuka, S., Tominaga, Y., Yu-Fat Lun, I., 2011. Up-scaling CWE models to include mesoscale meteorological influences. J. Wind Eng. Ind. Aerodyn. 99, 187-198.

Montazeri, H., Blocken, B., 2013. CFD simulation of wind-induced pressure coefficients on buildings with and without balconies: Validation and sensitivity analysis. Build. Environ. 60, 137-149.

OpenFOAM 2.3.0 Released. User Guide.

Pasquill, F., 1961. The estimation of the dispersion of windborne material. Meteorol. Mag. 90 (1063).

Patankar, S.V., 1980. Numerical Heat Transfer and Fluid Flow McGraw-Hill book company. (0-07-048740-5).

Pena, A., Hasager, C.B., Gryning, S.E., Courtney, M., Antoniou, I., Mikkelsen, T., 2009. Offshore wind profiling using light detection and ranging measurements. Wind Energy $12,105-124$

Plate, E.J., 1982. Wind tunnel modelling of wind effects in engineering. In: Plate, E.J. (Ed.), Engineering Meteorology. Elsevier, Amsterdam, pp. 573-639 (Chapter 13).

Plate, E.J., 1999. Methods of investigating urban wind fields - physical models. Atmos. Environ. 33, 3981-3989.

Repetto, M.P., 2011. Neutral and non-neutral atmosphere: probabilistic characterization and wind-induced response of structures. J. Wind Eng. Ind. Aerodyn. 99, 969-978.

Repetto, M.P., Burlando, M., Solari, G., De Gaetano, P., Pizzo, M., 2017a. Integrated tools for improving the resilience of seaports under extreme wind events. Sustain. Cities Soc. 32, 277-294.

Repetto, M.P., Burlando, M., Solari, G., De Gaetano, P., Pizzo, M., Tizzi, M., 2017b. A webbased GIS platform for the safe management and risk assessment of complex structural and infrastructural systems exposed to wind. Adv. Eng. Softw. 117, 29-45.

Ricci, A., Burlando, M., Freda, A., Repetto, M.P., 2017a. Wind tunnel measurements of the urban boundary layer development over a historical district in Italy. Build. Environ. 111, 192-206.
Ricci, A., Kalkman, I., Blocken, B., Burlando, M., Freda, A., Repetto, M.P., 2017b. Local-scale forcing effects on wind flows in an urban environment: impact of geometrical simplifications. J. Wind Eng. Ind. Aerodyn. 170, 238-255.

Ricci, A., Kalkman, I., Blocken, B., Burlando, M., Freda, A., Repetto, M.P., 2018. Large-scale forcing effects on wind flows in the urban canopy: impact of inflow conditions. Sustain. Cities Soc. 42, 593-610.

Richards, P.J., Hoxey, R.P., 1993. Appropriate boundary conditions for computational wind engineering models using the k- $\varepsilon$ turbulence model. J. Wind Eng. Ind. Aerodyn. 4647, 145-153.

Santiago, J.L., Martín, F., Martilli, A., 2013. A computational fluid dynamics modelling approach to assess the representativeness of urban monitoring stations. Sci. Total Environ. 454-455, 61-72

Santiago, J.L., Borge, R., Martín, F., de la Paz, D., Martilli, A., Lumbreras, J., Sanchez, B., 2017. Evaluation of a CFD-based approach to estimate pollutant distribution within a real urban canopy by means of passive samplers. Sci. Total Environ. 576, 46-58.

Sathe, A., Mann, J., 2013. A review of turbulence measurements using ground-based wind lidars. Atmospheric Measurement Techniques 6, 3147-3167.

Sathe, A., Mann, J., Gottschall, J., Courtney, M.S., 2011. Can wind lidars measure turbulence. Journal of Atmospheric Oceanic Technology 28, 853-868.

Schatzmann, M., Leitl, B., 2011. Issue with validation of urban flow and dispersion CFD models. J. Wind Eng. Ind. Aerodyn. 99, 169-186.

Sha, C., Wang, X., Lin, Y., Fan, Y., Chen, X., Hang, J., 2018. The impact of urban open space and 'lift-up' building design on building intake fraction and daily pollutant exposure in idealized urban models. Sci. Total Environ. 633, 1314-1328.

Shih, T.H., Liou, W.W., Shabbir, A., Zhu, J., 1995. A new k-ع eddy-viscosity model for high Reynolds number turbulent flows. Comput. Fluids 24, 227-238.

Smith, D.A., Harris, M., Coffey, A.S., 2006. Wind Lidar evaluation at the Danish wind test site in Høvsøre. Wind Energy 9, 87-93.

Solari, G., 2014. Thunderstorm monitoring modelling, response and loading of structures. Journal of Wind Engineering, Japan Association for. Wind Engineering 39 (4) 344-346.

Solari, G., Repetto, M.P., Burlando, M., De Gaetano, P., Parodi, M., Pizzo, M., Tizzi, M., 2012 The wind forecast for safety management of port areas. J. Wind Eng. Ind. Aerodyn. 104-106, 266-277.

Stull, R.B., 1988. An Introduction to Boundary Layer Meteorology. First ed. Springer, Netherlands 978-94-009-3027-8 ISBN.

Tominaga, Y., Stathopoulos, T., 2013. CFD simulation of near-field pollutant dispersion in the urban environment: a review of current modelling techniques. Atmos. Environ. 79, 716-730.

Tominaga, Y., Stathopoulos, T., 2016. Ten questions concerning modeling of near-field pollutant dispersion in the built environment. Build. Environ. 105, 390-402.

Tominaga, Y., Mochida, A., Yoshie, R., Kataoka, H., Nozu, T., Yoshikawa, M., et al., 2008. AI guidelines for practical applications of CFD to pedestrian wind environment around buildings. J. Wind Eng. Ind. Aerodyn. 96, 1749-1761.

van Hooff, T., Blocken, B., 2010. Coupled urban wind flow and indoor natural ventilation modelling on a high-resolution grid: a case study for the Amsterdam ArenA stadium. Environ. Model Softw. 25, 51-65.

van Hooff, T., Blocken, B., Tominaga, Y., 2017. On the accuracy of CFD simulations of crossventilation flows for a generic isolated building: comparison of RANS, LES and experiments. Build. Environ. 114, 148-165.

Vasaturo, R., Kalkman, I., Blocken, B., van Wesemael, P.J.V., 2018a. Large eddy simulation of the neutral atmospheric boundary layer: performance evaluation of three inflow methods for terrains with different roughness. J. Wind Eng. Ind. Aerodyn. 173 241-261.

Vasaturo, R., Kalkman, I., van Hoof, T., Blocken, B., van Wesemael, P.J.V., 2018b. Impact of passive climate adaptation measures and building orientation on the energy demand of a detached lightweight semi-portable building. Build. Simul. 11 (6), 1163-1177.

Venkatram, A., 1996. An examination of the Pasquill-Gifford-Turner dispersion scheme Atmos. Environ. 30, 1283-1290.

Wieringa, J., 1976. Representative roughness parameters for homogenous terrain. Boundary Layer Meteorology 63, 323-363.

Wilczak, J.M., Gossard, E.E., Neff, W.D., Eberhard, W.L., 1996. Ground-based remote sensing of the atmospheric boundary layer: 25 years of progress. Bound.-Layer Meteorol $78,321-349$.

Xie, Z., Castro, I.P., 2006. LES and RANS for turbulent flow over arrays of wall-mounted obstacles. Flow, Turbulence and Combustion 76, 291-312.

Xie, Z., Coceal, O., Castro, I.P., 2008. Large-eddy simulation of flows over random urban like obstacles. Bound.-Layer Meteorol. 129, 1-23.

Zhang, K., Chen, G., Wang, X., Liu, S., Mak, C.M., Fan, Y., Hang, J., 2019. Numerical evaluations of urban design technique to reduce vehicular personal intake fraction in deep street canyons. Sci. Total Environ. 653, 968-994. 